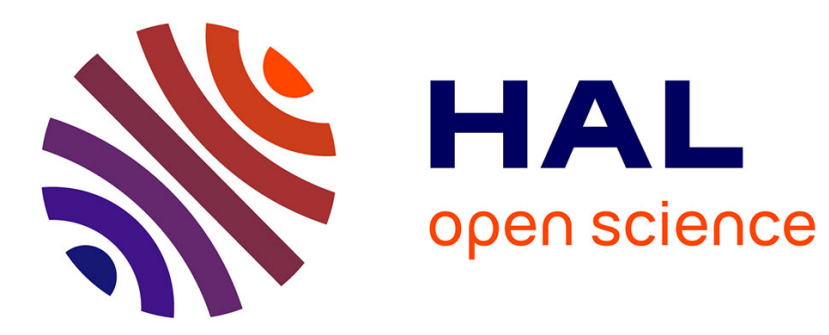

\title{
Statistical analysis for understanding and predicting battery degradations in real-life electric vehicle use
}

Anthony Barré, Frédéric Suard, Mathias Gérard, Maxime Montaru, Delphine Riu

\section{- To cite this version:}

Anthony Barré, Frédéric Suard, Mathias Gérard, Maxime Montaru, Delphine Riu. Statistical analysis for understanding and predicting battery degradations in real-life electric vehicle use. Journal of Power Sources, 2014, 245, pp.846-856. 10.1016/j.jpowsour.2013.07.052 . hal-01071585

\section{HAL Id: hal-01071585 https://hal.science/hal-01071585}

Submitted on 7 May 2019

HAL is a multi-disciplinary open access archive for the deposit and dissemination of scientific research documents, whether they are published or not. The documents may come from teaching and research institutions in France or abroad, or from public or private research centers.
L'archive ouverte pluridisciplinaire HAL, est destinée au dépôt et à la diffusion de documents scientifiques de niveau recherche, publiés ou non, émanant des établissements d'enseignement et de recherche français ou étrangers, des laboratoires publics ou privés. 


\title{
Statistical analysis for understanding and predicting battery degradations in real-life electric vehicle use
}

\author{
Anthony Barré ${ }^{\mathrm{a}, \mathrm{b}, *}$, Frédéric Suard $^{\mathrm{a}}$, Mathias Gérard ${ }^{\mathrm{b}}$, Maxime Montaru $^{\mathrm{b}}$, Delphine Riu $^{\mathrm{c}}$ \\ ${ }^{a}$ CEA, LIST, Information Models and Machine Learning, 91191 Gif sur Yvette CEDEX, France \\ ${ }^{b}$ CEA, LITEN, 17 rue des martyrs, 38054 Grenoble CEDEX 9, France \\ ${ }^{c}$ G2Elab, UMR 5269, 38402 Saint Martin d'Hères, France
}

\begin{abstract}
This paper describes the statistical analysis of recorded data parameters of electrical battery ageing during electric vehicle use. These data permit traditional battery ageing investigation based on the evolution of the capacity fade and resistance raise. The measured variables are examined in order to explain the correlation between battery ageing and operating conditions during experiments. Such study enables us to identify the main ageing factors. Then, detailed statistical dependency explorations present the responsible factors on battery ageing phenomena. Predictive battery ageing models are built from this approach. Thereby results demonstrate and quantify a relationship between variables and battery ageing global observations, and also allow accurate battery ageing diagnosis through predictive models.
\end{abstract}

Keywords: Li-ion battery, Battery degradation, Ageing, Prediction, Statistics, Electric Vehicle

\section{Introduction}

Lithium-ion rechargeable batteries have experienced a rapid growth in electric vehicles utilizations, due to their high energy and power density [1, 2]. However, the overall performance of batteries is not constant along the vehicle life. Reduction of battery performances are caused by various mechanisms and is characterized by a capacity fade as well as an impedance augmentation $[3,4,5]$. For an electric vehicle (EV) utilization, the battery ageing phenomena are characterized by a diminution of the global vehicle autonomy available with a full charge, whereas the global resistance augmentation provokes a reduction of peak acceleration.

These drawbacks are crucial to minimize the cost of the battery for EV uses $[6 \mid$. Thus, significant efforts have been achieved in order to understand the battery ageing process [7, 8, 9, 10, 11, 12]. Ageing phenomena are very complex due to the multi-scale and multi-physic phenomena interactions between the different physico-chemical reaction [13], so it is still challenging to implement a relevant model [14]. The aim for EV applications is to estimate the ageing level of the battery with few measurements, and with low complexity algorithms, in order to be compatible with industrial integration. Furthermore, ageing is a complex phenomenon, difficult to estimate with only few experiments and online constraints. All these constraints create a complicated compromise between the model accuracy and its complexity [15].

*Corresponding author : anthony.barre@cea.fr 
Most battery ageing studies are based on direct factors dependency and have limited prediction ability 16, 17, 18, 19, 20, 21]. These investigations mainly rely on simulated data, under controlled conditions, which is not totally representative of a real EV use [22]. This may occult ageing factor interactions [23]. Thus, real uses studies are particularly interesting in battery ageing understanding as it contains complementary informations than laboratory test. On the other hand, field testing induces major challenges as it requires long and complex protocols. Moreover, EV real-life utilization, under uncontrolled settings generates a large set of parameters which induces battery degradations.

In this work, a new method for battery ageing comprehension in EV conditions is presented to avoid drawbacks of current ageing studies. More precisely, statistical methods are used to identify the correlation between global ageing phenomena and operating conditions to allow an ageing estimation. Advantage of such study is that it permits the detection of possible unknown or misunderstood interactions, because no physical process is taken into account in the first analysis step. Furthermore, statistical methods enable us to obtain a quantification of dependences between several variables as well as impacts of each variable on the battery ageing. This approach in a battery ageing context is introduced in a recent study [24].

In this study, these methods are implemented to analyze the data obtained after a long test period of real uses. Main objectives of this study are the interpretation of the measured global ageing results and thereby the quantification of the impact of factors on each battery ageing phenomena. In order to enhance battery degradation understanding with an innovative statistical approach, this paper follows major steps :

- Collect entire recorded data during entire battery life

- Analyze the global battery life conditions

- Reduce the data with information conservation

- Identify and quantify the variables responsible of the battery degradation for each part of the battery life, with possible set interactions

- Develop predictive ageing models based on direct relevant recorded parameters

This paper follows this methodology, presenting in the part 2 the data collection process. Then, a macro analysis illustrates measured battery ageing results (part 3) followed by an exploration of utilization conditions during the experiment (part 4), with the aim to explain ageing results. This study demonstrates complex utilizations and leads to a deeper statistical approach in order to identify factors responsible of battery ageing (part 5). This permits the construction of battery ageing predictive models (part 5.4), based on statistical methods. Finally, this methodology is discussed in part 6 .

\section{Data collection}

\subsection{Materials}

This experiment is accomplished using an instrumented $\mathrm{LiFeO}_{4}$ (LFP) battery. The battery uses 10 modules composed of LiFeBatt cells, with the same initial characteristics: a $3.2 \mathrm{~V}$ nominal voltage and a $15 \mathrm{Ah}$ capacity. This battery design produces a nominal voltage of $400 \mathrm{~V}$ with a total capacity of $75 \mathrm{Ah}$ and an energy density of $80 \mathrm{Wh} / \mathrm{kg}$. Furthermore, the battery operates without 
thermal management. It is important to note that each full charge is done under a constant current, until the maximal voltage of $3.6 \mathrm{~V}$ is obtained, and includes a balancing period in order for every parallel branch to have the same voltage and to avoid loss of the global battery capacity.

During each charge or discharge, numerous variables are recorded at $10 \mathrm{~Hz}$ frequency. These variables are provided from vehicle position (longitude, latitude, altitude), its velocity (speed, GPS speed), and environment (ambient temperature, altitude, latitude, longitude, velocity...) and internal battery parameters (cells temperature, voltage, current...). Table 1 presents a detailed presentation of the 25 measured variables. Note that temperatures are measured on the surface of the elements. The total dataset recorded, available for detailed investigations, represents about $27 \mathrm{~Gb}$ only for utilization parts.

This test is distributed over a total period of 23 months with both uses and storage parts. The complete process is composed of three different modes. The first one uses a unique electric car (Figure 1), composed of a full electric power train. These driving experiments were done on the Michelin private test circuit (Figure 2), with a positive cumulative elevation difference of 255 meters by each $25 \mathrm{~km}$ lap [25]. In the second part of this test, the battery was stored in a controlled area during five months. The third part consists of power cycles on a test bench. During the fourth part, the battery had been reimplemented in a the electric car and used on the previous driving cycle conditions.

To summarize, the experiment is segmented in eight sessions, each of them containing a typical use period (cycle and/or storages) followed by a complete characterization (Figure 3).

The characterization tests (or check-up) always follow the same process. The tests are realized on an air conditioned room maintained at $25^{\circ} \mathrm{C}$. Initially the battery is fully charged at $\mathrm{C} / 9$ and is then entirely balanced. The battery is in rest during 1 hour before and after the charging period. After this charging period, the battery is subject to three power discharge models. The first one is a classic $\mathrm{C} / 2$ discharge and the two others are power discharge profiles chosen in the aim of performing a characterization under controlled conditions. These driving profiles have been defined according to the ARTEMIS Urbain [26] and the New European Driving Cycle (NEDC), helping to obtain an exhaustive diagnosis of the battery ageing. Hence, the capacity values are obtained by simple current integrations and the resistance values by current pulses.

\subsection{Driving cycle}

Driving experiments consisted in a repeated speed profile realized in the Michelin test circuit [25]. Using such private circuit is primordial in order to perfectly control the desired drive cycle. The same driving profile is realized by a unique professional driver reiterated over the whole experiment. The vehicle generally runs two consecutive laps $(50 \mathrm{~km})$ before a charging period. The objective and the advantage of a repeated speed profile is the observation of the consequence of battery ageing over time considering all parameters. Therefore, it helps analyzing the evolution of ageing on all different signals.

The driving cycle contains each of the different speed profiles to obtain a representative drive, such as stops and starts, low speed parts, stiff accelerations, constant speed situations etc. Thus, this profile represents the situations a battery can be faced with during its life in an electric vehicle use. The driving cycle had been modified at the beginning of the experiment because the battery elevation temperature was too high. The maximum speed limit initially provided at $140 \mathrm{~km} / \mathrm{h}$ was reduced to $100 \mathrm{~km} / \mathrm{h}$. This route generates elevated battery temperatures that obliged to modify this profile to finally suppress such high accelerations and to fix a long period to a constant speed of $100 \mathrm{~km} / \mathrm{h}$ after a month of experiments (Figure 4). 


\subsection{Storage cycle}

During about four months, the battery was stored within a box controlled at a constant temperature of $25^{\circ} \mathrm{C}$. This part of the experiment, done in the middle of the global process (session 5 ), permits to avoid a too intensive use of the battery which occults the calendar part of a battery ageing. Furthermore, it is interesting to investigate corresponding ageing results obtained in complete calendar conditions. This part is here important as a battery in use in an EV is stored a large majority of its life ( $>90 \%$ of the time), and ageing phenomena still occur during these periods.

\subsection{Bench cycle}

The bench cycle tests employ the same power profile as in driving cycle experiments, under a constant ambient temperature fixed at $25^{\circ}$. This profile is applied to the battery on a test bench in order to reproduce the power circuit solicitations but in a controlled temperature area. Such process permits to elude the environment effects (wind, rain, driver's bias...). Thus, the battery characterization parts can be assimilated to a bench cycle period, with a different power profile.

This utilization mode is similar to a vehicle to grid (V2Grid) use, where it is a stationary battery utilization. In this mode, some parameters such as distance or speed cannot be considered. This induces the non continuity of these parameters depending on a driving utilization. However, despite this particular stationary cycle, ageing process occurs during this kind of utilization, and consequently the battery performances are altered.

\section{Experiments results}

\subsection{General observations}

A total of $13077 \mathrm{kWh}$ are delivered by the battery through the experiment, with a distance of approximately $44038 \mathrm{~km}$ covered by a unique electric vehicle, and the other part resulting of bench tests. This corresponds to an average consumption of $218 \mathrm{Wh} / \mathrm{km}$ in vehicle uses. The driving sessions consumptions are close to each other which produces a direct linearity between the consumed energy and the distance. This notion induces our future choice during the ageing analysis.

Furthermore, the regeneration part amounted to some $6 \%$ of the total output energy. Hence, the total battery efficiency is near $91 \%$ which is a remarkable result [27, 28] (Table 2).

The battery was cycled a total time of 565 cumulative cycling days which represents around $20 \%$ of the global experiment time. To have an order of magnitude, in common vehicles the cycling time is less than $8 \%$ [3]. Thus, in this experiment, the utilization was intensive compared to an individual use, but the storage is still the main period of the battery life. Consequently, battery storage has an important part on ageing for real vehicle utilization. Therefore, it is primordial to examine these storage conditions for the ageing observations.

\subsection{Capacity fade}

A global consequence of an aged battery is the capacity fade [29, 30, 31, 32]. This characteristic corresponds to a loss of active lithium ions over time and a decrease of the electrodes active surface [33]. The obtained results show this phenomenon as the battery nominal capacity decrease over days of use (Figure 5). Results also illustrate a loss of battery capacity in a nonlinear way with delivered energy which induces a complex ageing process due to the linearity of every driving cycle (Figure 6). However, the capacity fade is nearly a linear function of the experimental days. The fluctuations are here probably the consequences of different use conditions. This point will be more detailed in the following parts. 


\subsection{Resistance growth}

The other major impact of battery ageing is an augmentation of the global battery resistance [34, 35, 36]. The achieved evolution of the resistance is a nonlinear evolution of the battery resistance (Figure 5). Resistance evolution is here a major issue due to its complex behavior (Figure 6). The resistance evolution decreased during the first session and increased after $2000 \mathrm{kWh}$ delivered by the battery, followed by a diminution during the long storage period (session 5), and finally in the last two sessions the resistance value is relatively stable.

Chemically, an explanation of the battery resistance augmentation is, inter alia, the SEI (Solid Electrolyte Interphase) formation and its expansion through the battery life [37, 38, 39]. This phenomenon induces a diminution of the maximum available power that implies a lower maximum acceleration of the vehicle. However, the chemical studies cannot totally explain the resistance behavior obtained here under real use conditions. Consequently, the aim of the paper is to understand the factors responsible for these battery ageing variables evolutions.

\section{Data analysis}

The objective of the following part is to analyze more precisely the previous results and to identify the most influent variables in battery degradations over time for both ageing consequences. In order to pinpoint the impacting factors on the battery ageing, it is significant to study the environmental conditions that the battery has undergone during its life. This part aims to explore battery life conditions whether the battery is used or not, and to identify factors impacting the battery health.

\subsection{Calendar life conditions}

Calendar conditions refer to the storage periods of the battery. According to several studies, the relevant factors during battery storage are the initial State Of Charge (SOC), the storage time and the ambient temperature [40, 41, 42]. In this experience the storage conditions are not fully controlled. Hence, storages follow a real life use as the temperature is most often subject to climate changes and the SOC is not controlled.

The most important notion in a calendar life is the storage time. Results presented in Table 3 represent longer cumulative storage time during fifth session which is composed only of a storage period and of a complete characterization.

Furthermore, the storage temperatures study confirms the trend that most severe conditions during the last part of experiments have been observed (sessions 5, 6 and 7). More specifically, the battery storage temperatures are similar during the three first experiments. During the fourth and eighth session of the experience, there is a considerable decrease of storage temperatures, due to external climate, but is still an acceptable level for a battery [40]. On the contrary, during the fifth, sixth and seventh sessions, the storage temperatures are high because of the test room control temperature. This observation is in good agreement with the linear decrease of capacity loss observed during these sessions (Figure 5,6).

The storage initial SOC level is also one of the admitted factors of battery ageing during its calendar life. According to these studies [32, 43], a high SOC level $(>70 \%)$, or a low one $(<30 \%)$, engenders a huge potential disequilibrium on the electrode/electrolyte interface and this accelerates chemical reactions. All through this experiment, the battery was under extreme SOC $(>90 \%$ or $<10 \%)$ quite often during each use session. However, most of storages happened during the fifth 
session (Table 3), and the SOC level is here considered at a critical low level (Figure 7). This observation can also explain the ageing results of the fifth session.

Thus, these storage variables observations illustrate the important interactions between ageing factors and storage conditions. It produces complex interactions, hence it is difficult to estimate individually the impact of these variables in order to quantify the calendar life influencing on the global battery ageing.

\subsection{Duty cycle conditions}

The level of constraints imposed on the battery during a driving test or a bench test leads to different degradations. The variables known as impacting cycle ageing directly come from the internal battery. Moreover, these variables result from the interaction between the utilization mode and the environment conditions. To illustrate these interactions, the battery temperature is directly impacted by the ambient temperature and the power delivered by the battery is affected by wind, slope etc.

Firstly, the battery temperature during driving periods produces similar results as calendar temperature study. The main observation is the high battery temperature during the bench test sessions (6 and 7) due to the room temperature (Figure 8).

The peak current measured drops significantly over time (Figure 9). This is quite notable as this maximum current instantly delivered takes place at the same time in the driving cycles. Thus the battery is supposed to be subject to the same constraints for the driving sessions due to the constant velocity profile. It is important to note that the bench sessions are not represented here because the bench material limit reduces the peak demand. This diminution of the maximum current is here interesting, as it is directly related to the battery degradations over time.

Moreover, $\triangle \mathrm{SOC}$ represents the state of charge variation during a charge or a discharge [44]. It is an indicator of the battery use in term of the amount of charge transited. A high value of $\triangle$ SOC provokes a battery power loss [45, 46] and consequently the development of SEI which is engendered by high discharge (or charge). The $\triangle \mathrm{SOC}$ repartition illustrates the driving process as most are between 30 and $50 \%$, which is characteristic of the average discharge by each vehicle run. Note that these conditions of a medium $\triangle \mathrm{SOC}$ are not the most constraining situation for the battery in terms of degradations. Moreover, there are no significant differences of this parameter between each session (Figure 10). For the stationary cycles (sessions 6 and 7), the battery are mainly used shortly, which explains the low $\Delta \mathrm{SOC}$ values $(\Delta \mathrm{SOC}<10)$. Consequently there is no possible conclusion based on the $\Delta \mathrm{SOC}$ due to the close conditions between the sessions.

In order to examine the accuracy of the driving cycle through sessions, a driving pattern estimator is calculated. This indicator is the Positive Kinetic Energy (PKE) [47]. This parameter is a positive value resulting of the profile accelerations. Positive Kinetic Energy (PKE) is defined as the sum of the differences between the squares of the final and initial speeds in successive acceleration, divided by total trip distance $D$, where the speed $v$ is expressed in meters per second:

$$
P K E=\frac{\sum_{i}\left(v_{i+1}^{2}-v_{i}^{2}\right)}{D}, v_{i+1}>v_{i}
$$

Thus, the obtained PKE values demonstrate the regularity of the driving profile through sessions (Figure 11). The only exception occurs in the first session as the speed profile was initially defined with accelerations through $140 \mathrm{~km} / \mathrm{h}$. Thereby, battery degradations differences between driving sessions cannot be associated to the use mode or to the driver's behavior, but to other parameters variations. 
Other variables as average speed or charging voltage, may induce accelerated battery degradations. It is not the case here as during this experiment the charging strategy is always the same. Hence, this does not permit the investigation of these ageing factors.

The obtained results are complex to interpret, based on a simple variables analysis due to the several interactions inducing the battery degradation.

\subsection{Summary of battery life conditions}

This part of the study focuses on experiment conditions and highlights long and constraining storage periods. Thus, it is primordial to consider the calendar ageing in a global ageing survey since this represents a large part of the entire battery life. Many models exist to predict a calendar ageing approximation but none help to obtain a good accuracy due to the interaction of each storage condition [29].

The cycle ageing analysis produces illustrations of both ageing causes and consequences. Through the experiments the peak power declines and on the other hand the $\Delta \mathrm{SOC}$ repartition shows a reasonable utilization in term of discharge depth. It is quite difficult to quantify the impact of each factor on the global ageing phenomena obtained. Main interactions between variables could not be identified with direct variables study. Nevertheless, this method is largely used to identify the impactful variables and to quantify their respective effects. Indeed, battery ageing is known as a complex phenomenon resulting from numerous and various factors coming from utilization mode and environment. Hence, a simple variable analysis cannot perform well to detect interactions.

All these reasons justify the complexity of an exhaustive ageing comprehension. Thus, models can hardly perform very precisely on ageing estimation and diagnostic on account of the involvement of many different factors. Furthermore, such methods as well as electrochemical models require the absolute identification of each interaction in order to be accurate.

\section{Statistical study}

The multiple interactions during the whole battery life made a real remaining challenge of the battery ageing estimation. In this manner, it is necessary to study every variable in order to cover all the phenomena. This brings the concept of statistical studies, as such methods could discover hidden interactions and thus can allow a battery ageing comprehension. Furthermore, a statistical study also permits to quantify the factors effects on the battery degradation, and can generate predictive ageing models.

\subsection{Factors interactions}

The first aim of this kind of method is to reduce the number of variables without loss of information. In this method, there is no assumption about variables coming from battery measures or from the environment conditions (ambient temperature, GPS position...), during the utilization test on the circuit. The initial principle of considering each variable permits to avoid preliminary error and to not delete potential interactions. According to this idea each measured variable is considered at the beginning of this study. The methods used are correlation [48] as well as mutual information investigations [49, 50].

A battery cycle is here defined as both charging and discharging period. Concerning the discharging part, some results are expected as it is always the same cycle profile and thus the energy transit, utilization time and distance are constant in each driving cycle. Consequently, it is implicit to find a complete correlation between variables representing in a certain way these notions. Indeed, 
the results confirm that the test time and the distance traveled are directly related in this intensive test. These results are illustrated by the linear correlations approach [48], presented in Figure 12.

During the battery charging time, few variables reveal a complete linear relationship. This is due to the charging voltage that is constant through the whole experiment and therefore the energy transit is linear with time. Moreover, some results are the same on both battery cycle parts. Mainly, these results show that variable measurements at a cell level are not necessary and it does not add information compared to the same variable measured at a global battery level. For example the temperature, the current, the voltage and the transit energy taken from the battery level contain the same information as the ones taken from a cell (Figure 12). Thus for example, the correlation coefficient is higher of $95 \%$ between a cell temperature and the battery temperature.

After this correlations study, it appears that some variables contain the same information as others. For example, the accessories voltage is correlated to the kilometers and the charges number and the transited battery energy values are dependent.

All these results permit to create a reduced group of relevant variables and minimize the factors dimension without loss of information. Hence, from the 25 initial variables remain only 14 parameters.

\subsection{Factors impacting battery ageing}

The main objective of this study is the battery ageing comprehension according to the experimental data. This part consists of a study of the dependency exploration. It concerns directly battery ageing diagnosis obtained from characterizations. More specifically, the investigation is focused on the correlation between each variable and the results of battery ageing.

Firstly, measured variables signals are compressed to a value per session. In some cases, a simple value is not representative of the signal distribution and other variables are introduced. For example, the current profile oscillates and an average value would erase important information. In order to consider every notion, other concepts are explored: the maximum of current peak, the number of current sign changes, $\triangle \mathrm{SOC}$ repartition, storage conditions (duration, temperature, SOC).

A new database is formed from all of these variables and values of capacity and resistance measured at each characterization. A preliminary study permits to remove factors identified as independent to both battery ageing phenomena: capacity fade and resistance growth.

Consequently, observations can be made on the ageing impact of each remaining variables. This approach and the conclusion obtained can be divided into two parts: the reasons of the capacity fade and the resistance raise. In order to explore the whole battery life, studies are done with two point of views: both degradation phenomena separately for each session and the global degradations together, sustained by the battery during each session.

- Each degradation phenomena separately : in the first case, a correlation is calculated on both ageing phenomenon measured. Hence, the impact of variable units is related to a level of degradation. Figure 13 presents the relationship between capacity fade and the variable units for each session. For each variable and each session, the calculated correlation coefficient is representative of the variable impact in the capacity loss in this particular session. Thus, Figure 13 reveals a high correlation between the capacity loss during the fifth session and its duration (storage or experience days). Similarly, the capacity fade occurring in the seventh session seems to be linked to the high temperatures. 
The same approach with the resistance growth induces more complex interpretations (Figure 14). With the same interpretations, the seventh session appears to be constrained in the sense of current alternation and cycle numbers. On the contrary, in the first session each parameter has the same impact and no interpretation can be made.

- Ageing phenomena together : the aim is to obtain information based on multi-interactions. The approach is here a normalized Principal Component Analysis (PCA) [51] study. This method permits to explore ageing factors and their respective impact. Thus, each ageing phenomenon is associated with different relevant variables. The interpretation of such results is that the capacity loss seems to be related to ambient temperature and storage conditions. However, the resistance evolution is highly dependent on the current signal and the energy transit. The normalized PCA confirms these observations and permits to obtain an illustration of factors dependences (Figure 15). Thus in this Figure 15, variables that neighbor each other generally have positive correlations while those that linearly oppose generally have negative correlations. Hence, this analysis highlights two distinct groups related to battery ageing:

- The capacity fade : time, temperatures and storage time etc.

- Resistance raise : current profile (speed, I max, $\triangle \mathrm{SOC}$ ), energy transit and cycles number etc.

\subsection{Understanding battery degradations through battery life conditions}

This part is a summary and interpretation of results obtained through these studies for each main battery ageing phenomenon with real electric vehicle utilization.

- Capacity fade: The measured loss of capacity resulting from the test shows a difference between sessions. Results previously presented demonstrate a strong linear relationship between the capacity evolution and time dependent variables. Moreover, the capacity diminution is a function of temperatures and storages. Time impacts directly the capacity whereas the cycle stress seems to slightly interact with the battery resistance.

- Resistance raise: According to this work, resistance is significantly related to the driving cycle. More precisely, the resistance raise seems in interaction with the maximum current delivered by the battery and with the power profile in general. Thus, during the storage fifth session, the resistance decreases which confirms this hypothesis. Hence, the resistance evolution is here related to the constraint imposed by the use mode: power profile, speed, $\triangle \mathrm{SOC}$ cycle number. This notion is important for the ageing comprehension.

\subsection{Battery ageing degradations predictive models}

Based on these conclusions, the natural extension is to construct an ageing model from few variables measured by the battery. The method considered here is a linear model, in the aim to predict a real-valued output $Y$ based on a vector of inputs $X=\left(X_{1}, \ldots, X_{n}\right)$, following the Equation (2).

$$
Y=f(X)=\beta_{0}+\sum_{j=1}^{n} X_{j} \beta_{j}
$$


In the specific application of this study, $X$ is an input matrix $(P \times n)$, corresponding to the $n$ relevant variables measured during the $P$ sessions. The equation (2) provides a degradation prediction $\hat{Y}=f(W)$, from new observations vector $W$. The aim is to estimate the parameters $\beta$ of this linear model. The applied methods, presented in the following parts correspond to the automatic model-building algorithms.

\subsubsection{Forward selection}

The forward selection is a stepwise regression, starting with no variables in the model and adding one-by-one variables until some accuracy criterion is fulfilled. The next variable to be included can be chosen based on a number of criteria. In this study, the method chooses the variable that has the highest absolute correlation with the residual vector [52].

\subsubsection{Least angle regression}

Least Angle Regression (LARS) is a regression method providing a soft method of forward selection [53]. The LARS algorithm also starts with empty an set of active variables. As the forward selection, the correlation between each variable and the response are measured, the variable with the highest correlation becomes the first variables included into the model. The first direction is then towards the least squares solution using this single active variable. Going in this direction, the angles between the variables and the residual vector are measured. Along this, the angles will change; in particular, the correlations between the residual vector and the active variable shrinks linearly towards zero. At some moment before this point, another variable obtains the same correlation with respect to the residual vector as the active variable. The walk stops and the new variable is added to the active set. The new direction of the walk is towards the least squares solution of the two active variables, and so on. After a number of steps, the full least squares solution will be reached.

\subsubsection{Ridge regression}

The ridge regression shrinks the regression coefficients by imposing a penalty on their size [54]. The optimal parameters $\hat{\beta}^{\text {ridge }}$ minimize a penalized residual sum of squares, with $s \geq 0$ a tuning parameter (Equation (3)).

$$
\hat{\beta}^{\text {ridge }}=\underset{\beta}{\operatorname{argmax}} \sum_{i=1}^{P}\left(y_{i}-\beta_{0}-\sum_{j=1}^{n} x_{i j} \beta_{j}\right)^{2}, \text { subject to } \sum_{j=1}^{n} \beta_{j}^{2} \leq s
$$

\subsubsection{Last absolute shrinkage and selection operator}

The Last Absolute Shrinkage and Selection Operator (lasso [55]), like the ridge regression, is a technique implementing coefficient shrinkage and selection. The $L_{2}$ ridge penalty $\sum_{j=1}^{n} \beta_{j}^{2}$ is

replaced by the $L_{1}$ lasso penalty $\sum_{j=1}^{n}\left|\beta_{j}\right|$. The optimal parameters $\hat{\beta}^{\text {lasso }}$ are defined by Equation (4), with $t \geq 0$ a bound parameter.

$$
\hat{\beta}^{\text {lasso }}=\underset{\beta}{\operatorname{argmax}} \sum_{i=1}^{P}\left(y_{i}-\beta_{0}-\sum_{j=1}^{n} x_{i j} \beta_{j}\right)^{2} \text {, subject to } \sum_{j=1}^{n}\left|\beta_{j}\right| \leq t
$$




\subsubsection{Elastic net}

As an automatic variable selection method, the elastic net method overcomes the precedent methods limitation, combining the $L_{1}$ and $L_{2}$ penalties of the lasso and ridge methods [56]. The estimation from the elastic net method are defined by Equation (6), using Equation (5).

$$
\begin{gathered}
\hat{\beta}^{*}=\underset{\beta}{\operatorname{argmin}} \sum_{i=1}^{P}\left(y_{i}-\beta_{0}-\sum_{j=1}^{n} x_{i j} \beta_{j}\right)^{2}-\lambda_{1} \sum_{j=1}^{n}\left|\beta_{j}\right|-\lambda_{2} \sum_{j=1}^{n} \beta_{j}^{2}, \text { with } \lambda_{1}>0, \lambda_{2}>0 \\
\hat{\beta}^{\text {ElasticNet }}=\left(1+\lambda_{2}\right) \hat{\beta}^{*}
\end{gathered}
$$

\subsubsection{Predictive models results}

In the battery ageing context, as explained in the previous sections, both battery ageing phenomena have different evolutions. Then, different mathematical models are built, one to predict battery capacity and one to estimate battery resistance. In order to obtain these models, the presented methods are applied on ageing results, with input variables coming from the battery utilizations measured at each session.

This methodology permits to construct models based on the measurements from the $1^{\text {st }}$ session to the $i^{t h}$, and predicts the battery ageing values from the $i+1^{t h}$ session. Hence, the models are build with the first recordings, and tested at different instants, providing a comparison of models performances through data considered to build the models (Table 4).

Results illustrate the accuracy of models for capacity evolution prediction, as the prediction error rate is lower than $1 \%$, for most of estimated degradations, in the presented models. This can be explained as the capacity evolution is constantly decreasing and the variations of the capacity evolution slope are low. Only the LARS method does not perform significantly before the last prediction.

On the contrary, the resistance evolution is more complex and models require larger learning data to perform with a good accuracy. Hence, the estimation of the battery resistance made after the characterization five are far from the real resistance evolution. However, from the prediction made after the characterization five, the lasso method provides very low error rates (Table 4).

Figure 16 presents, for each method, the estimated capacity of the characterizations 6, 7 and 8, based on previous observations. This results illustrate the good accuracy of the predictive models in the battery capacity prediction, especially with the forward selection. Figure 17 presents the predictions of the battery resistance made after the characterization six, clearly showing the performances of the lasso technique in these estimations.

The presented methods do not use all of the considered variables to construct models, this point is particularly interesting in the battery ageing context, permitting the identification of the variables related to the ageing phenomena. Table 5 presents the selected variables by the best models of ageing phenomena : forward selection for capacity evolution, and lasso for resistance evolution. The interesting point is the low number of variable selected by these algorithms. Thus, selected variables illustrate and confirm the points demonstrated in part 5.1, here is a summary of these impacting parameters :

- Capacity evolution : time (experimental days, output energy, distance) and storage conditions (temperature) 
- Resistance evolution : time (output energy, cycles number, distance), usage conditions (ambient and battery temperature), utilization profiles constraint (I sign alternation, PKE, $\Delta$ SOC)

It it important to observe the perfect agreement with the conclusion made in the part 5.1 and the selected variables, separating both ageing phenomena and their respective impacting parameters. Furthermore, battery ageing predictive accuracy provides high confidence in these results. Thus, presented statistical methods demonstrate high accuracy level in predictions, associated with an interesting interpretation of selected variables.

\section{Discussion}

The proposed statistical approach provides an innovative way to explore the battery ageing comprehension and estimation. Simple data analysis presented in part 4. does not allows the substantiation of the obtained battery ageing (Figure 5,6). Thus, deeper data study, introduced in part 5 , demonstrates the ability of statistical methods to identify the influential variables of both battery ageing phenomena, in accordance with electrochemical investigations. Hence, the paper methodology selects these variables, allowing the comprehension of obtained battery ageing. Both battery ageing phenomena, capacity fade and resistance growth, are respectively associated to different measured variables. This point is particularly interesting in the aim of avoiding premature battery ageing, by applying limitations of certain variables, identified as impacting battery performance degradations. Indeed, the methodology leads to the understanding of the detailed battery degradation causes (part 5.3), which is primordial in the EV use context.

The predictive ageing models introduced in part 5.4 provide a high accuracy in both battery ageing phenomena estimation, permitting a battery diagnosis with only few measurements. Moreover, this approach is also particularly adapted in the ageing comprehension study as the models use only a part of the input variables to make a prediction. Hence, the selected variables supply the demonstration of part 5.2, as both conclusions are in total agreement. Thus, the capacity fade prove to be associated to time and storage conditions. Similarly, the resistance growth proves to be related to the utilization conditions (temperatures, current profile...). This result isextremely important as it demonstrates the causes of both battery ageing phenomena.

The next step of this methodology is to study data coming from a large fleet of EV, providing an amount of informations permitting a better accuracy of these conclusions. Different uses conditions could permit to obtain more accurate and robust predictive models. Moreover, predictive models are here used on a unique type of battery and it will be interesting to observe their performances and robustness on other battery designs and chemistry.

\section{Conclusion}

This paper describes a battery life experiment for an electric vehicle use. The aim of our work is to study the main causes of battery ageing through data analysis. A huge dataset has been recorded during a real vehicle usage over twenty-three months of intensive use. Due to the experimental aspect of such experiment, a large amount of data has been retained to inform about both battery parameters and environmental conditions.

The specificity of the presented approach is to base the analysis on statistical tools. This kind of algorithms is particularly adapted to deal with multivariate time signals and helps us pinpoint the main variables responsible for battery ageing. Then we propose to identify over time the evolution of 
all of these variables influence. Another major advantage of such an approach resides in the ability to identify independently both resistance and capacity evolution causes. Based on this study, the evoked methodology creates simple and accurate battery ageing prediction models.

Pure statistical methods have demonstrated a good ability to give a proof of a-priori opinions and thus quantify the impact of each ageing factor. These analyses clearly illustrate the existence of multiple interactions between ageing phenomena. Furthermore, results demonstrate the huge complexity of the battery ageing diagnosis and the identification of impacting factors. This kind of method looks very promising in terms of better ageing comprehension and prediction. However, results are based on data from one battery and it would require more diversity to be effective in every context.

Therefore it would be very interesting to apply this methodology with larger data, coming from a large vehicle fleet, thereby obtaining more accurate results in order to discover and understand ageing phenomena. Indeed, more data will allow deeper statistical methods and consequently enable better battery ageing mechanisms. This would allow the construction of more precise ageing prediction models, with only few measurements done in real time during the battery life. As more and more data are saved, it will be interesting to oversee the development of such methods in battery ageing comprehension and estimation over time.

\section{Acknowledgments}

The authors are grateful to Gino Paganelli and Olivier Joye of Michelin for their contribution on CEA pack integration into Michelin vehicle named WILL and for performing intensive tests on Michelin circuit. This work was supported by French agency ADEME into the "AMI - Demonstration project for new energy technologies".

\section{References}

[1] B. Scrosati, J. Garche, Lithium batteries: Status, prospects and future, Journal of Power Sources 195 (9) (2010) 2419 - 2430. doi:10.1016/j.jpowsour.2009.11.048. URL http://www.sciencedirect.com/science/article/pii/S0378775309020564

[2] A. Ritchie, W. Howard, Recent developments and likely advances in lithium-ion batteries Journal of Power Sources 162 (2) (2006) 809 - 812, special issue including selected papers from the International Power Sources Symposium 2005 together with regular papers. doi:10.1016/j.jpowsour.2005.07.014. URL http://wWw. sciencedirect.com/science/article/pii/S0378775305008670

[3] M. Kassem, J. Bernard, R. Revel, S. Pélissier, F. Duclaud, C. Delacourt, Calendar aging of a graphite/lifepo4 cell, Journal of Power Sources 208 (0) (2012) 296 - 305. doi:10.1016/j.jpowsour.2012.02.068. URL http://www. sciencedirect.com/science/article/pii/S0378775312004284

[4] T. Yoshida, M. Takahashi, S. Morikawa, C. Ihara, H. Katsukawa, T. Shiratsuchi, J. ichi Yamaki, Degradation mechanism and life prediction of lithium-ion batteries, Journal of the Electrochemical Society 153 (2006) 576-582. 
[5] S. Bourlot, P. Blanchard, S. Robert, Investigation of aging mechanisms of high power li-ion cells used for hybrid el Journal of Power Sources 196 (16) (2011) 6841-6846, 15th International Meeting on Lithium Batteries (IMLB).

[6] J. Neubauer, A. Brooker, E. Wood, Sensitivity of battery electric vehicle economics to drive patterns, vehicle range Journal of Power Sources (0) (2012)-.

[7] J. Remmlinger, M. Buchholz, M. Meiler, P. Bernreuter, K. Dietmayer, State-of-health monitoring of lithium-ion batteries in electric vehicles by on-board internal resistance estimation, Journal of Power Sources 196 (12) (2011) 5357 - 5363, Selected papers presented at the 12th Ulm ElectroChemical Talks (UECT):2015 Technologies on Batteries and Fuel Cells. doi:10.1016/j.jpowsour.2010.08.035. URL http://www.sciencedirect.com/science/article/pii/S0378775310013534

[8] R. Spotnitz, Simulation of capacity fade in lithium-ion batteries, Journal of Power Sources 113 (1) (2003) 72 - 80. doi:10.1016/S0378-7753(02)00490-1. URL http://www.sciencedirect.com/science/article/pii/S0378775302004901

[9] L. Gao, S. Liu, R. A. Dougal, Dynamic lithium-ion battery model for system simulation, IEEE Tansacations on Components and Packaging Technologies 25 (3) (2002) 495 - 505.

[10] U. Tröltzsch, O. Kanoun, H.-R. Tränkler, Characterizing aging effects of lithium ion batteries by impedance spectr Electrochimica Acta 51 (8-9) (2006) 1664 - 1672, electrochemical Impedance Spectroscopy Selection of papers from the 6th International Symposium (EIS 2004) 16-21 May 2004, Cocoa Beach, FL, USA. doi:10.1016/j.electacta.2005.02.148. URL http://www.sciencedirect.com/science/article/pii/S0013468605007899

[11] O. Bohlen, J. Kowal, D. U. Sauer, Ageing behaviour of electrochemical double layer capacitors: Part i. experiment Journal of Power Sources 172 (1) (2007) 468 - 475, aCS San Francisco 2006 Fuel and Cell Symposium. American Chemical Society National Meeting. San Francisco, CA Sept 10-14 2006. doi:10.1016/j.jpowsour.2007.07.021. URL http://www.sciencedirect.com/science/article/pii/S0378775307014802

[12] A. Eddahech, O. Briat, H. Henry, J.-Y. Delétage, E. Woirgard, J.-M. Vinassa, Ageing monitoring of lithium-ion cell during power cycling tests, Microelectronics Reliability 51 (9-11) (2011) 1968 - 1971, proceedings of the 22th European Symposium on the Reliability Of Electron Devices, Failure Physics And Analysis. doi:10.1016/j.microrel.2011.07.013 URL http://www.sciencedirect.com/science/article/pii/S0026271411002769

[13] J. Zhu, K. Zeng, L. Lu, Cycling effects on surface morphology, nanomechanical and interfacial reliability of limn2o Electrochimica Acta 68 (0) (2012) $52-59$.

[14] P. L. Taberna, S. Mitra, P. Poizot, P. Simon, J.-M. Tarascon, High rate capabilities fe3o4based cu nano-architectured electrodes for lithium-ion battery applications, Nature Materials 5 (2006) 567-573.

[15] A. Barré, B. Deguilhem, S. Grolleau, M. Gérard, F. Suard, D. Riu, A review on lithium-ion battery ageing mechanisms and estimations for automotive applications, Journal of Power Sources 241 (0) (2013) 680 - 689. doi:10.1016/j.jpowsour.2013.05.040 
[16] Y. Xing, Q. Miao, T. K.-L, P. M., Prognostics and health monitoring for lithium-ion battery, Intelligence and Security Informatics (ISI), 2011 IEEE International Conference on (2011) $242-247$.

[17] V. Marano, S. Onori, Y. Guezennec, G. Rizzoni, N. Madella, Lithium-ion batteries life estimation for plug-in hybrid electric vehicles, Vehicle Power and Propulsion Conference, 2009. VPPC '09. IEEE (2009) 536-543.

[18] H. Wenzl, I. Baring-Gould, R. Kaiser, B. Y. Liaw, P. Lundsager, J. Manwell, A. Ruddell, V. Svoboda, Life prediction of batteries for selecting the technically most suitable and cost effective battery Journal of Power Sources 144 (2) (2005) 373 - 384, selected papers from the Ninth European Lead Battery Conference. doi:10.1016/j.jpowsour.2004.11.045. URL http://www.sciencedirect.com/science/article/pii/S0378775304011231

[19] B. Y. Liaw, R. G. Jungst, G. Nagasubramanian, H. L. Case, D. H. Doughty, Modeling capacity fade in lithium-ion cells, Journal of Power Sources 140 (1) (2005) 157 161. doi:10.1016/j.jpowsour.2004.08.017. URL http://www.sciencedirect.com/science/article/pii/S0378775304008808

[20] A. D. Filippi, S. Stockar, S. Onori, M. Canova, Y. Guezennec, Model-based life estimation of li-ion batteries in phevs using large scale vehicle simulations: An introductory study (2010).

[21] M. Ecker, J. B. Gerschler, J. Vogel, S. Käbitz, F. Hust, P. Dechent, D. U. Sauer, Development of a lifetime prediction model for lithium-ion batteries based on extended accelerated aging test dat Journal of Power Sources (0) (2012) -.

[22] M. Dubarry, C. Truchot, B. Y. Liaw, Synthesize battery degradation modes via a diagnostic and prognostic model Journal of Power Sources 219 (0) (2012) $204-216$.

[23] S. S. Zhang, A review on electrolyte additives for lithium-ion batteries, Journal of Power Sources 162 (2) (2006) 1379 - 1394, Special issue including selected papers from the International Power Sources Symposium 2005 together with regular papers. doi:10.1016/j.jpowsour.2006.07.074. URL http://wWw.sciencedirect.com/science/article/pii/S0378775306017538

[24] A. Barré, F. Suard, M. Gérard, M. Montaru, D. Riu, Statistical method tools to analyze ageing effects on li-ion battery performances, SAE 2013 World Congress \& Exhibition doi:10.4271/2013-01-1429.

[25] [link].

URL http://www . michelin-engineering-and-services . com/mes/front/affich . jsp?codeRubrique=2006061

[26] M. André, The artemis european driving cycles for measuring car pollutant emissions, Science of The Total Environment 334-335 (0) (2004) 73 - 84, Highway and Urban Pollution. doi:10.1016/j.scitotenv.2004.04.070 URL http://www.sciencedirect.com/science/article/pii/S0048969704003584

[27] S. Dhameja, Electric vehicle battery systems, Newnes, 2002.

[28] M. Eberhard, M. Tarpenning, The 21st century electric car, Tech. rep., Tesla Motors (2006). 
[29] M. Dubarry, B. Y. Liaw, M.-S. Chen, S.-S. Chyan, K.-C. Han, W.-T. Sie, S.-H. Wu, Identifying battery aging mechanisms in large format li ion cells, Journal of Power Sources 196 (7) (2011) 3420 - 3425. doi:10.1016/j.jpowsour.2010.07.029. URL http://www.sciencedirect.com/science/article/pii/S0378775310012127

[30] A. T. Stamps, C. E. Holland, R. E. White, E. P. Gatzke, Analysis of capacity fade in a lithium ion battery, Journal of Power Sources 150 (0) (2005) 229 - 239. doi:10.1016/j.jpowsour.2005.02.033. URL http://www.sciencedirect.com/science/article/pii/S037877530500251X

[31] G. Ning, B. Haran, B. N. Popov, Capacity fade study of lithium-ion batteries cycled at high discharge rates, Journal of Power Sources 117 (1-2) (2003) 160 - 169. doi:10.1016/S0378-7753(03)00029-6. URL http://www.sciencedirect.com/science/article/pii/S0378775303000296

[32] Q. Zhang, R. E. White, Capacity fade analysis of a lithium ion cell, Journal of Power Sources 179 (2) (2008) 793 - 798. doi:10.1016/j.jpowsour.2008.01.028 URL http://www.sciencedirect.com/science/article/pii/S0378775308001134

[33] J. Vetter, P. Novák, M. Wagner, C. Veit, K.-C. Möller, J. Besenhard, M. Winter, M. Wohlfahrt-Mehrens, C. Vogler, A. Hammouche, Ageing mechanisms in lithium-ion batteries, Journal of Power Sources 147 (1-2) (2005) 269 - 281. doi:10.1016/j.jpowsour.2005.01.006 URL http://www.sciencedirect.com/science/article/pii/S0378775305000832

[34] F. Huet, A review of impedance measurements for determination of the state-of-charge or state-of-health of secon Journal of Power Sources 70 (1) (1998) 59 - 69. doi:10.1016/S0378-7753(97) 02665-7. URL http://www.sciencedirect.com/science/article/pii/S0378775397026657

[35] M. Kerlau, M. Marcinek, V. Srinivasan, R. M. Kostecki, Studies of local degradation phenomena in composite cathodes for lithium-ion batteries, Electrochimica Acta 52 (17) (2007) 5422 - 5429. doi:10.1016/j.electacta.2007.02.085 URL http://www.sciencedirect.com/science/article/pii/S0013468607003234

[36] K. Amine, C. Chen, J. Liu, M. Hammond, A. Jansen, D. Dees, I. Bloom, D. Vissers, G. Henriksen, Factors responsible for impedance rise in high power lithium ion batteries, Journal of Power Sources 97-98 (0) (2001) 684-687, proceedings of the 10th International Meeting on Lithium Batteries. doi:10.1016/S0378-7753(01)00701-7. URL http://www.sciencedirect.com/science/article/pii/S0378775301007017

[37] S.-P. Kim, A. C. van Duinb, V. B. Shenoya, Effect of electrolytes on the structure and evolution of the solid electro $\begin{array}{llllll}\text { Journal of Power } & \text { Sources } & 196 \quad(20) & (2011) & 8590-8597 .\end{array}$ doi:10.1016/j.jpowsour.2011.05.061. URL http://www. scopus. com/inward/record.url?eid=2-s2.0-79961025152\&partnerID=40\&md5=ee0322eba0

[38] S. Zhang, K. Xu, T. Jow, Eis study on the formation of solid electrolyte interface in li-ion battery, Electrochimica Acta 51 (8-9) (2006) 1636 - 1640, electrochemical Impedance Spectroscopy Selection of papers from the 6th International Symposium (EIS 2004) 16-21 May 2004, Cocoa Beach, FL, USA. doi:10.1016/j.electacta.2005.02.137. URL http://www.sciencedirect.com/science/article/pii/S0013468605007966 
[39] H. Buqa, A. Würsig, J. Vetter, M. Spahr, F. Krumeich, P. Novák, Sei film formation on highly crystalline graphitic materials in lithium-ion batteries, Journal of Power Sources 153 (2) (2006) 385 - 390, selected papers presented at the 2004 Meeting of the International Battery Association 2004 International Meeting of the International Battery Association. doi:10.1016/j.jpowsour.2005.05.036. URL http://www.sciencedirect.com/science/article/pii/S0378775305007317

[40] J. Belt, V. Utgikar, I. Bloom, Calendar and phev cycle life aging of high-energy, lithium-ion cells containing blende $\begin{array}{llllllll}\text { Journal of } & \text { Power Sources } 196 \quad(23) & (2011) & 10213 & -\end{array}$ doi:10.1016/j.jpowsour.2011.08.067. URL http://www.sciencedirect.com/science/article/pii/S0378775311016107

[41] M. Broussely, S. Herreyre, P. Biensan, P. Kasztejna, K. Nechev, R. Staniewicz, Aging mechanism in li ion cells and calendar life predictions, Journal of Power Sources 9798 (0) (2001) $13-21$, proceedings of the 10th International Meeting on Lithium Batteries. doi:10.1016/S0378-7753(01)00722-4 URL http://www.sciencedirect.com/science/article/pii/S0378775301007224

[42] Q. Zhang, R. E. White, Calendar life study of li-ion pouch cells, Journal of Power Sources 173 (2) (2007) 990 - 997, polish Conference on Systems with Fast Ionic Transport. doi:10.1016/j.jpowsour.2007.08.044. URL http://www. sciencedirect.com/science/article/pii/S0378775307015911

[43] R. P. Ramasamy, R. E. White, B. N. Popov, Calendar life performance of pouch lithium-ion cells, Journal of Power Sources 141 (2) (2005) 298 - 306. doi:10.1016/j.jpowsour.2004.09.024 URL http://wWw.sciencedirect.com/science/article/pii/S0378775304010687

[44] P. Liu, J. Wang, J. Hicks-Garner, E. Sherman, S. Soukiazian, M. Verbrugge, H. Tataria, J. Musser, P. Finamore, Aging mechanisms of lifepo4 batteries deduced by electrochemical and structural analyses, Journal of The Electrochemical Society 157 (4) (2010) A499-A499. URL http://link.aip.org/link/JESOAN/v157/i4/pA499/s1\&Agg=doi

[45] I. Bloom, B. Cole, J. Sohn, S. Jones, E. Polzin, V. Battaglia, G. Henriksen, C. Motloch, R. Richardson, T. Unkelhaeuser, D. Ingersoll, H. Case, An accelerated calendar and cycle life study of li-ion cells, Journal of Power Sources 101 (2) (2001) $238-247$. doi:10.1016/S0378-7753(01)00783-2.

URL http://www.sciencedirect.com/science/article/pii/S0378775301007832

[46] J. R. Belt, C. D. Ho, C. G. Motloch, T. J. Miller, T. Q. Duong, A capacity and power fade study of li-ion cells during life cycle testing, Journal of Power Sources 123 (2) (2003) 241 - 246. doi:10.1016/S0378-7753(03)00537-8. URL http://www.sciencedirect.com/science/article/pii/S0378775303005378

[47] E. Ericsson, Independent driving pattern factors and their influence on fuel-use and exhaust emission factors, Transportation Research Part D: Transport and Environment 6 (5) (2001) $325-345$. doi:10.1016/S1361-9209(01)00003-7. URL http://www.sciencedirect.com/science/article/pii/S1361920901000037 
[48] J. L. Rodgers, A. W. Nicewander, Thirteen ways to look at the correlation coefficient, The American Statistician 42 (1) (1988) 59-66. doi:10.2307/2685263.

URL http://dx.doi.org/10.2307/2685263

[49] L. Batina, B. Gierlichs, E. Prouff, M. Rivain, F. S. and. N. Veyrat-Charvillon, Mutual information analysis : a comprehensive study, Journal of Cryptology 24 (2010) 269-291.

[50] W. Li, Mutual information functions versus correlation functions, Journal of Statistical Physics 60 (1990) 823-837.

[51] I. Jolliffe, Principal Component Analysis, Encyclopedia of Statistics in Behavioral Science, 2005.

[52] R. H. Myers, Classical and modern regression with applications.

[53] B. Efron, T. Hastie, I. Johnstone, R. Tishirani, Least angle regression, The Annals of Statistics 32 (2) (2004) 407-499.

[54] A. E. Hoerla, R. W. Kennarda, Ridge regression : Biased estimation for nonorthogonal problems, Technom 12 (1) (1970) 55-67.

[55] R. Tibshirani, Regression shrinkage and selection via the lasso, Journal of the Royak Statistical Society, Series B (Methodological) 58 (1996) 267-288.

[56] H. Zou, T. Hastie, Regularization and variable selection via the elastic net, Journal of the Royal Statistical Society: Series B (Statistical Methodology) 67 (2) (2005) 301-320. doi: $10.1111 / j .1467-9868.2005 .00503 . x$ URL http://dx.doi.org/10.1111/j.1467-9868.2005.00503.x 


\section{List of tables}

Table 1. Names and descriptions of measured variables during experiments

Table 2. Summary of the global performances results by session

Table 3. Summary of the calendar storage conditions of the battery by session

Table 4. Error rate of battery ageing prediction models

Table 5. Selected variables of predictive battery ageing models

\section{List of figures}

Figure 1. The electric car used during driving tests

Figure 2. The Michelin test circuit employed during the experiments

Figure 3. Illustration of the global progress of experiments over time

Figure 4. Speed profile used during driving experiments

Figure 5. Results of the battery capacity loss and the internal battery resistance over days

Figure 6. Results of the battery capacity loss and the internal battery resistance over delivered energy

Figure 7. Repartition of battery initial storage SOC for each session - after kernel smoothing

Figure 8. Repartition of the battery average temperatures for each session - after kernel smoothing Figure 9. Evolution of the maximum current delivered by the battery over sessions - after kernel smoothing

Figure 10. Repartition of the $\triangle \mathrm{SOC}$ for each session - after kernel smoothing

Figure 11. Repartition of the PKE measured in driving tests for each session - after kernel smoothing Figure 12. Absolute value of the correlation coefficient between variables during discharge periods Figure 13. Dependency coefficient between variables and the capacity evolution for each session, normalized by session

Figure 14. Dependency coefficient between variables and the resistance evolution for each session, normalized by session

Figure 15. Normalized Principal Component Analysis variable vector map

Figure 16. Results of the battery capacity evolution predictive models - calculated from the sixth characterization

Figure 17. Results of the battery resistance evolution predictive models - calculated from the seventh characterization 


\begin{tabular}{|c|c|}
\hline Origin & Variables description \\
\hline Vehicle & $\begin{array}{r}\text { Distance covered and time of the current discharge (distance, time) }), \\
\text { vehicle speed }(\text { speed }), \text { cumulative kilometers covered }(\text { kilometers })\end{array}$ \\
\hline GPS & Vehicle position $($ longitude, latitude, altitude), and speed $($ GPS speed $)$ \\
\hline $\begin{array}{c}\text { Battery } \\
\text { measures }\end{array}$ & $\begin{array}{c}\text { Cumulative number of charges }(\text { charges number }), \text { SOC }(S O C), \\
\text { instantaneous battery temperature, current and voltage }(T \text { battery, I battery, } U \text { battery }), \\
\text { input, output and consumed energy }(E \text { bat input, E bat output, E bat consumed })\end{array}$ \\
\hline $\begin{array}{c}\text { Cell } \\
\text { measures }\end{array}$ & $\begin{array}{r}\text { Minimum and maximum cell temperature }(T \text { cell min, T cell max }), \\
\text { and voltage }(U \text { cell min, } U \text { cell max })\end{array}$ \\
\hline Others & $\begin{array}{c}\text { Ambient temperature }(T \text { ambient }), \text { wheels informations }(\text { wheels thorque }) \\
\text { Accessories voltage }(U \text { accessories }), \text { traction current }(I \text { traction }), \text { I battery acc????????? }\end{array}$ \\
\hline
\end{tabular}

Table 1: Names and descriptions of all measured variables during experiments

\begin{tabular}{|c|c|c|c|c|c|c|c|}
\hline Session & Type & $\begin{array}{c}\text { Distance } \\
(\boldsymbol{k m})\end{array}$ & \multicolumn{2}{|c|}{ Given energy (kWh) } & Capacity loss & $\begin{array}{c}\text { Consumption } \\
\text { (Wh } / \boldsymbol{k g})\end{array}$ & $\begin{array}{c}\text { Cycles } \\
\text { numbers }\end{array}$ \\
\hline Dr.1 & Driving & 9304 & 2019 & 248 & 1.95 & 190 & 189 \\
\hline Dr.2 & Driving & 10318 & 2431 & 171 & 3.46 & 220 & 279 \\
\hline Dr.3 & Driving & 9623 & 1993 & 126 & 1.85 & 140 & 267 \\
\hline Dr.4 & Driving & 5714 & 1300 & 75 & 0.85 & 215 & 164 \\
\hline St.5 & Storage & $\mathrm{x}$ & 205 & 205 & 1.32 & $\mathrm{x}$ & 14 \\
\hline Be.6 & Bench & $\mathrm{x}$ & 1482 & 152 & 1.41 & $\mathrm{x}$ & 197 \\
\hline Be.7 & Bench & $\mathrm{x}$ & 943 & 122 & 0.95 & $\mathrm{x}$ & 234 \\
\hline Dr.8 & Driving & 10079 & 2704 & 200 & 1.71 & 248 & 343 \\
\hline
\end{tabular}

Table 2: Summary of the global performances results by session 


\begin{tabular}{|c|c|c|c|}
\hline Name & $\begin{array}{c}\text { Cumulative } \\
\text { time } \\
(\text { days })\end{array}$ & $\begin{array}{c}\text { Average } \\
\text { initial SOC } \\
(\boldsymbol{\%})\end{array}$ & $\begin{array}{c}\text { Average } \\
\text { temperature } \\
\left({ }^{\circ} \mathrm{C}\right)\end{array}$ \\
\hline Dr.1 & 59 & 61.17 & 18.67 \\
\hline Dr.2 & 56 & 53.71 & 21.23 \\
\hline Dr.3 & 54 & 92.01 & 19.85 \\
\hline Dr.4 & 46 & 46.56 & 12.22 \\
\hline St.5 & 151 & 39.21 & 25.16 \\
\hline Be.6 & 46 & 72.03 & 27.70 \\
\hline Be.7 & 29 & 72.05 & 26.00 \\
\hline Dr.8 & 115 & 57.99 & 16.16 \\
\hline
\end{tabular}

Table 3: Summary of the calendar storage conditions of the battery by session

\begin{tabular}{|c|c||c|c|c||c|c|c|}
\hline \multicolumn{1}{|c||}{ Method } & \multicolumn{5}{c|}{ Prediction error rate (\%) } \\
Name & Check-Up & 6 & 7 & 8 & 6 & 7 & 8 \\
\hline \hline \multirow{3}{*}{ Forward } & $0-5$ & $\mathbf{- 0 . 3 0}$ & $\mathbf{- 0 . 2 0}$ & $\mathbf{0 . 4 6}$ & -5.47 & -31.62 & 37.91 \\
& $0-6$ & $\mathrm{X}$ & $\mathbf{0 . 0 6}$ & $\mathbf{0 . 1 2}$ & $\mathrm{X}$ & -29.70 & 37.78 \\
& $0-7$ & $\mathrm{X}$ & $\mathrm{X}$ & -0.44 & $\mathrm{X}$ & $\mathrm{X}$ & 2.62 \\
\hline \multirow{3}{*}{ LARS } & $0-5$ & -0.29 & -1.36 & 1.06 & -6.37 & -0.43 & 15.19 \\
& $0-6$ & $\mathrm{X}$ & -2.87 & 2.45 & $\mathrm{X}$ & 5.37 & 8.57 \\
& $0-7$ & $\mathrm{X}$ & $\mathrm{X}$ & -0.33 & $\mathrm{X}$ & $\mathrm{X}$ & 3.25 \\
\hline \multirow{3}{*}{ Ridge } & $0-5$ & $\mathbf{- 0 . 3 7}$ & $\mathbf{- 0 . 5 3}$ & $\mathbf{0 . 2 0}$ & -3.76 & 3.03 & 7.68 \\
& $0-6$ & $\mathrm{X}$ & -0.22 & -0.31 & $\mathrm{X}$ & 5.31 & 4.53 \\
& $0-7$ & $\mathrm{X}$ & $\mathrm{X}$ & -0.86 & $\mathrm{X}$ & $\mathrm{X}$ & 7.38 \\
\hline \multirow{3}{*}{ Lasso } & $0-5$ & -0.51 & 1.27 & -0.77 & -7.95 & -3.47 & 11.43 \\
& $0-6$ & $\mathrm{X}$ & 1.45 & -1.45 & $\mathrm{X}$ & $\mathbf{0 . 1 4}$ & $\mathbf{- 0 . 1 4}$ \\
& $0-7$ & $\mathrm{X}$ & $\mathrm{X}$ & $\mathbf{0}$ & $\mathrm{X}$ & $\mathrm{X}$ & $\mathbf{0}$ \\
\hline \multirow{3}{*}{ Elastic } & $0-5$ & 0.21 & 0.61 & -0.83 & -8.89 & -5.28 & 17.53 \\
Net & $0-6$ & $\mathrm{X}$ & 0.53 & -0.63 & $\mathrm{X}$ & 0.35 & 4.35 \\
& $0-7$ & $\mathrm{X}$ & $\mathrm{X}$ & -0.32 & $\mathrm{X}$ & $\mathrm{X}$ & 5.04 \\
\hline
\end{tabular}

Table 4: Error rate of battery ageing prediction models 


\begin{tabular}{|c|c||c|c||c|c|}
\hline \multicolumn{1}{|c||}{} & \multicolumn{2}{c||}{ Capacity } & \multicolumn{2}{c|}{ Resistance } \\
\hline \multicolumn{1}{|c||}{ Method } & \multicolumn{2}{c|}{ Forward } & \multicolumn{2}{c|}{ Lasso } \\
Variables & Check-Up & $0-5$ & $0-6$ & $0-6$ & $0-7$ \\
\hline \multicolumn{2}{|c||}{ Output energy } & $\checkmark$ & $\checkmark$ & $\checkmark$ & $\checkmark$ \\
I sign alternation & $\checkmark$ & $\checkmark$ & $\checkmark$ & $\checkmark$ \\
Distance & $\checkmark$ & $\checkmark$ & $\checkmark$ & $\checkmark$ \\
Storage temperature & $\checkmark$ & $\checkmark$ & & \\
Experimental days & & $\checkmark$ & & \\
Ambient temperature & & & $\checkmark$ & $\checkmark$ \\
Cycles number & & & $\checkmark$ & $\checkmark$ \\
PKE & & & $\checkmark$ & $\checkmark$ \\
DSOC & & & $\checkmark$ & $\checkmark$ \\
Battery temperature & & & & $\checkmark$ \\
\hline \multicolumn{2}{|l}{}
\end{tabular}

Table 5: Selected variables of predictive battery ageing models 


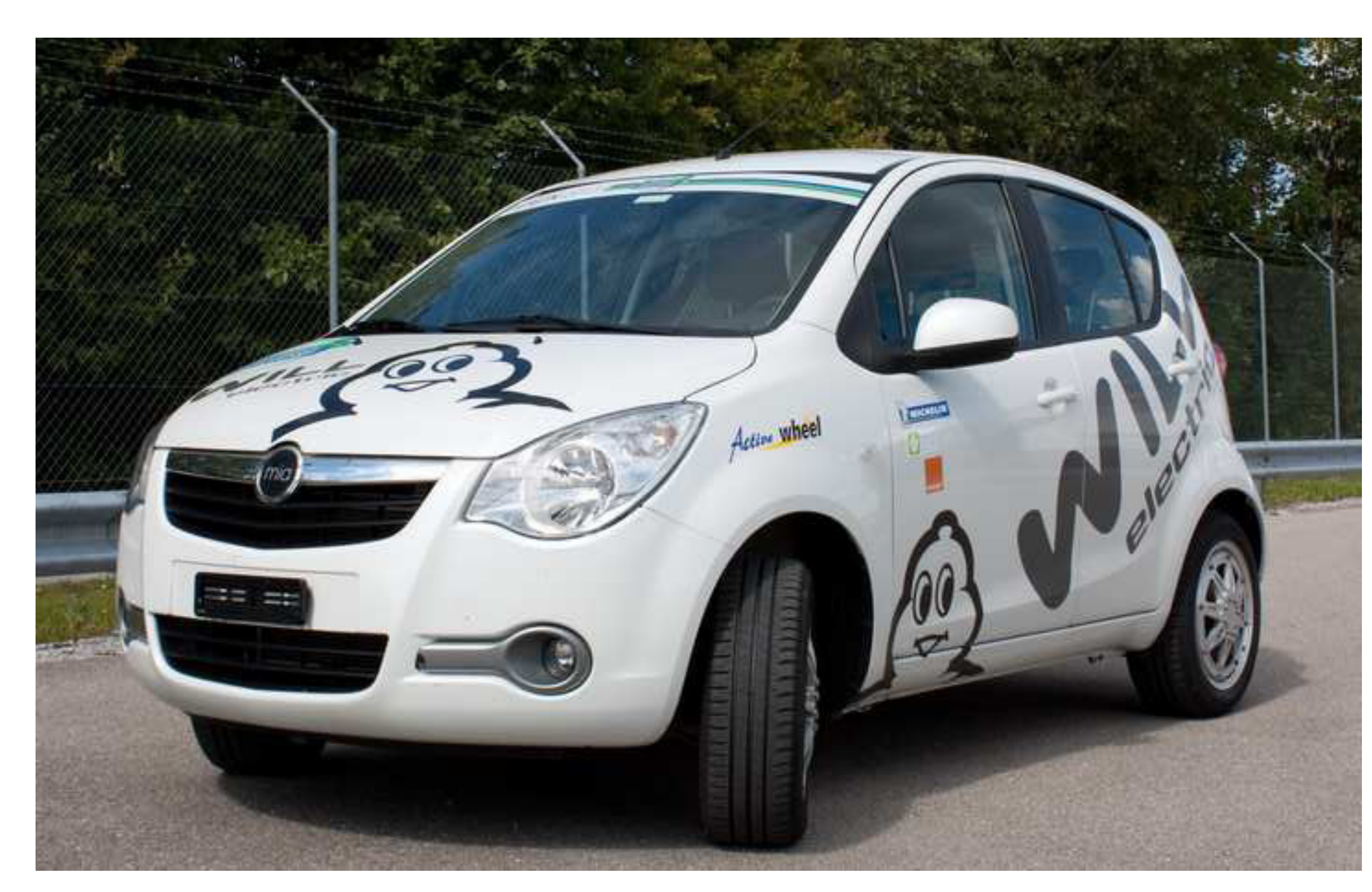


Click here to download high resolution image

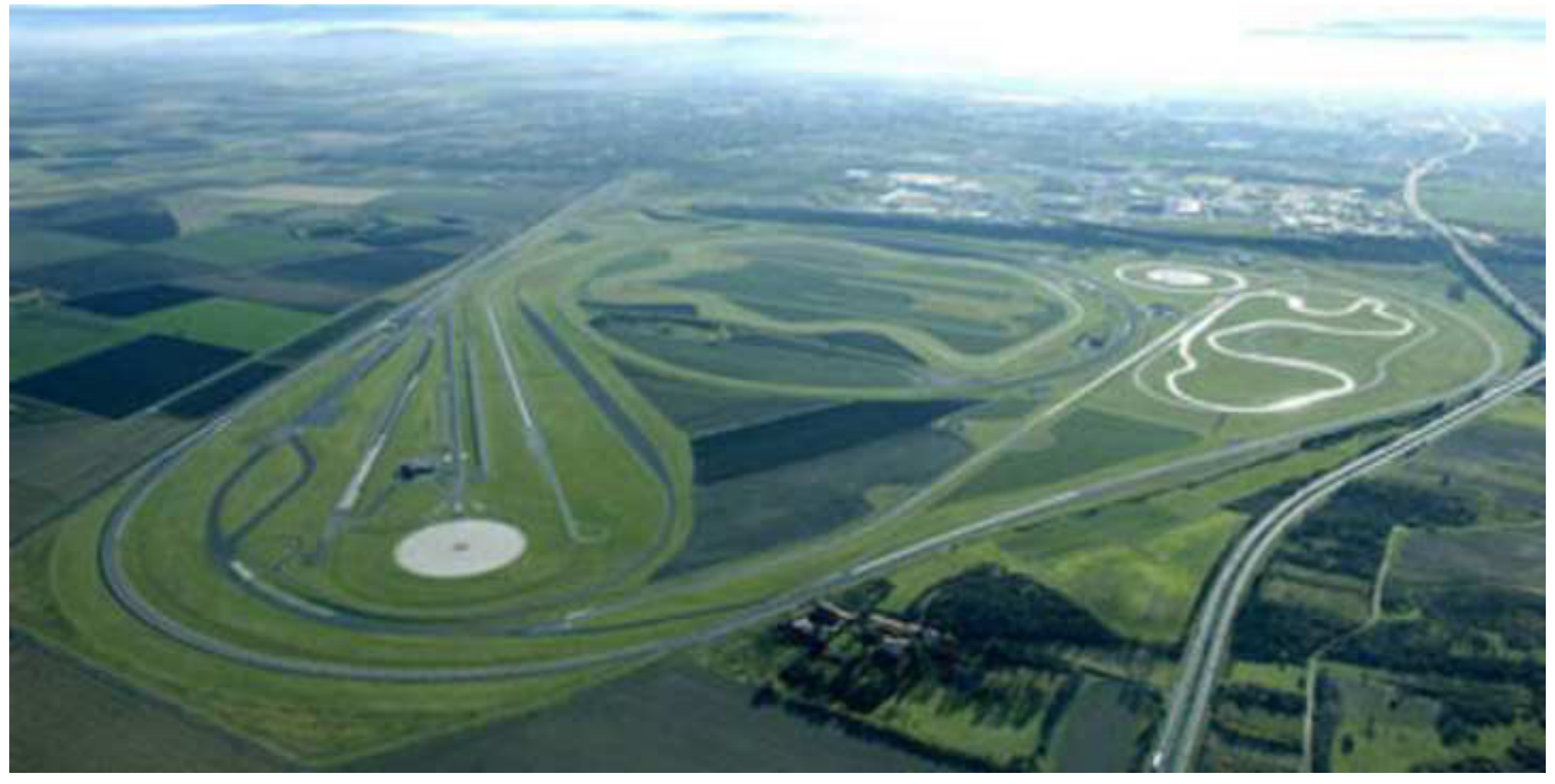

Figure 2

Clck here to download high resolution image 
Figure 4

Click here to download Figure(s): Speed.eps

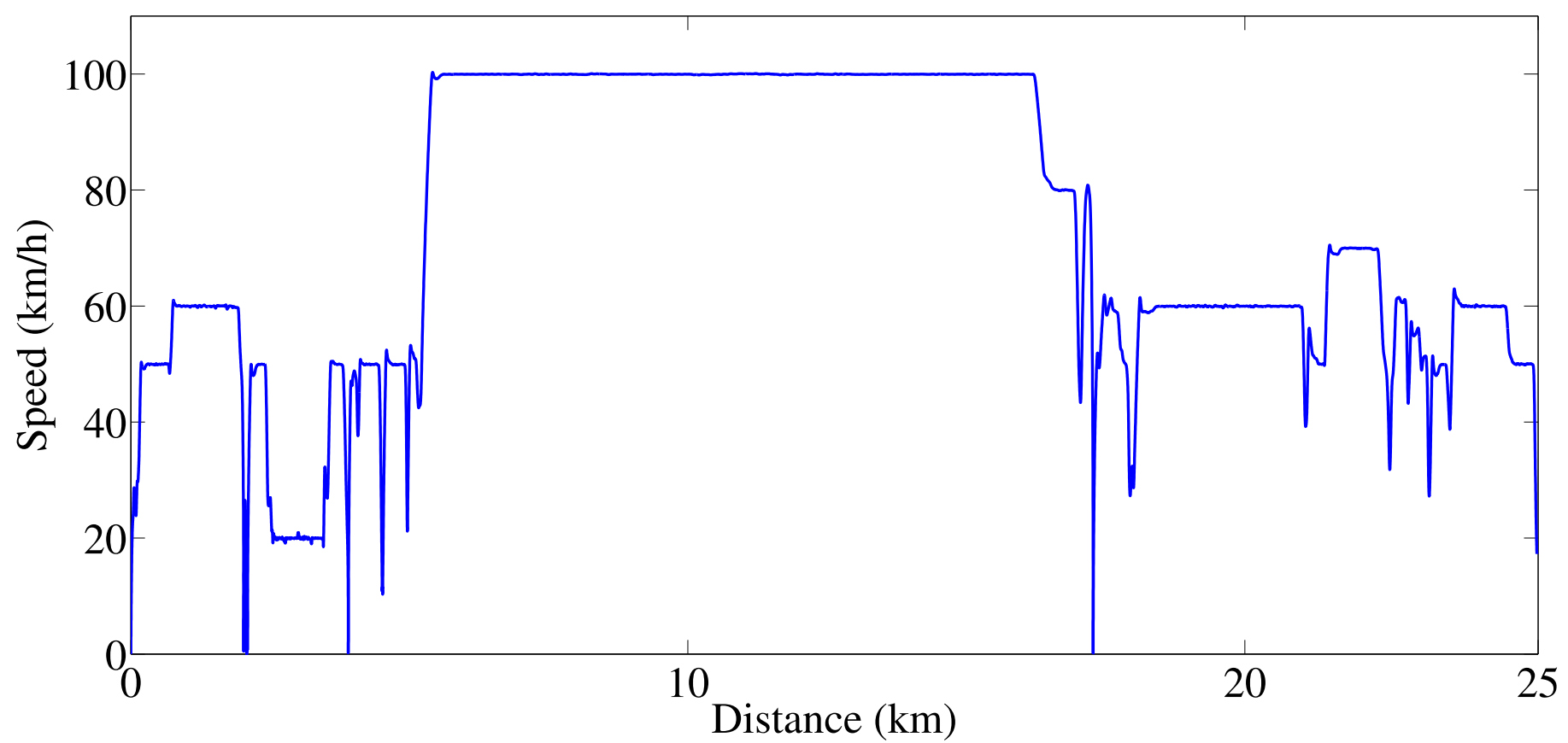




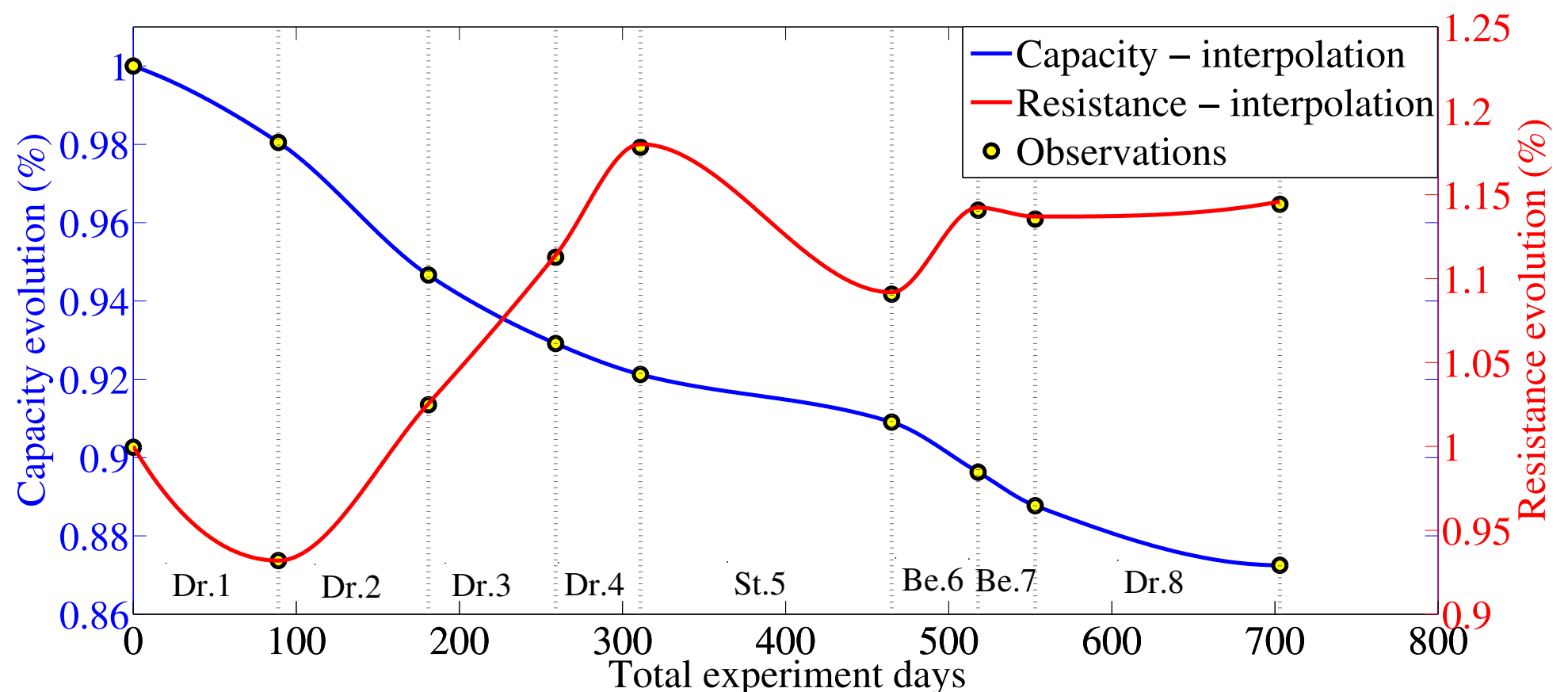




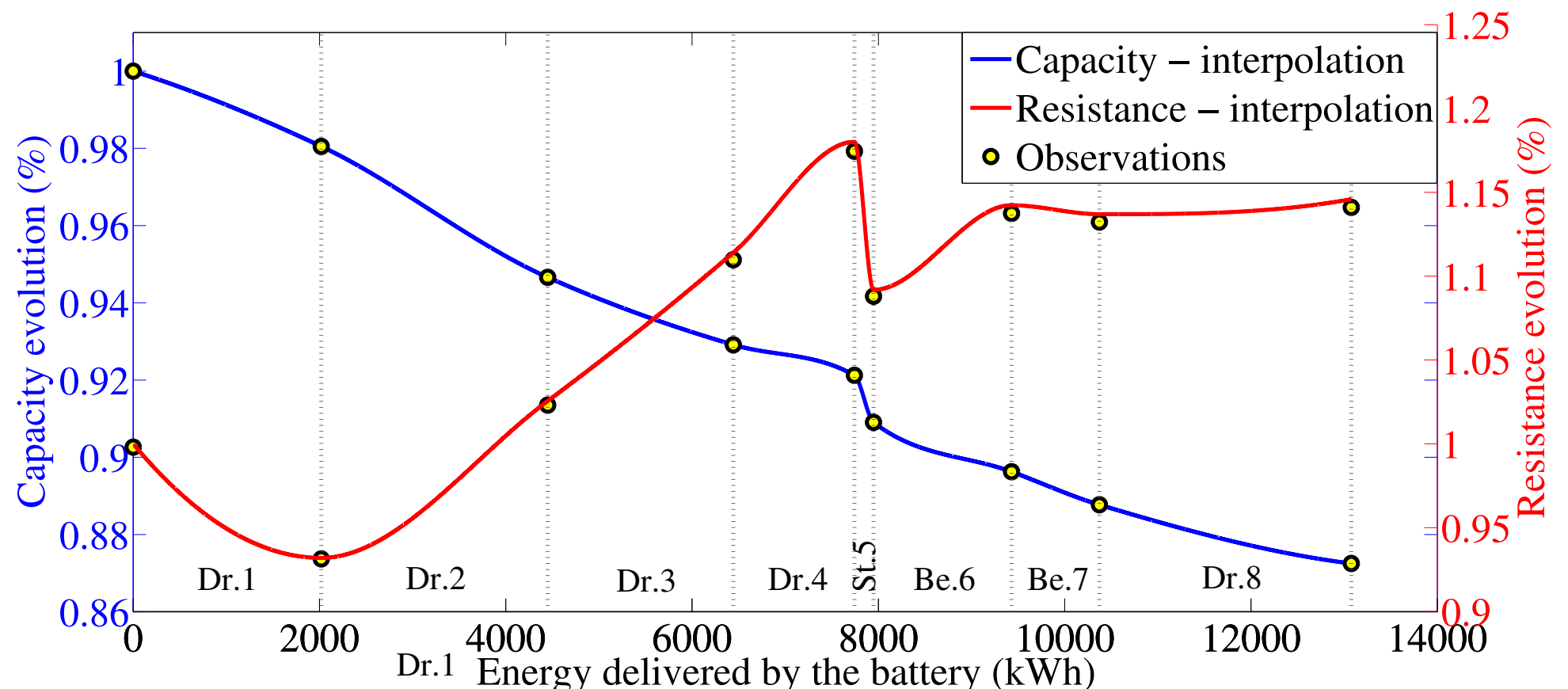




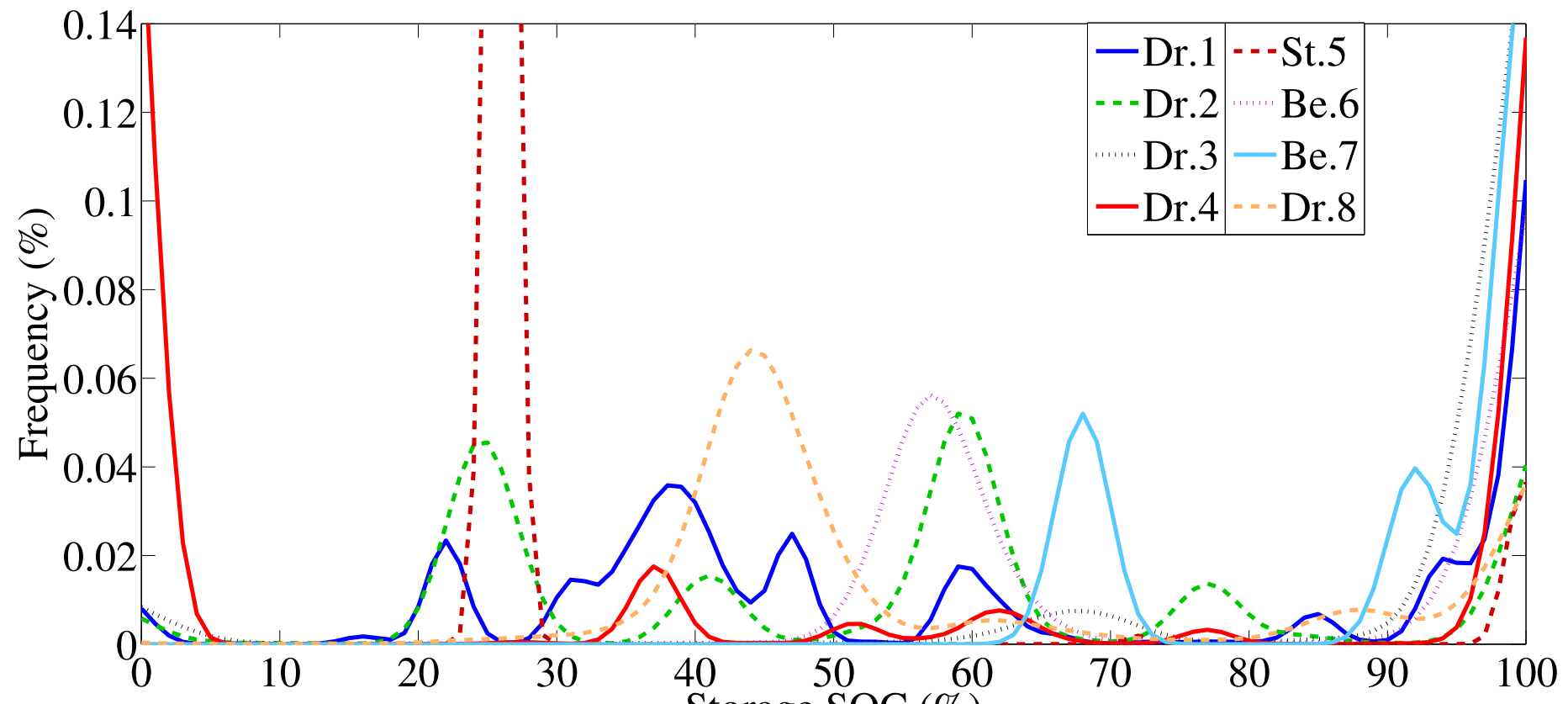

Storage SOC (\%) 
Figure 8
Click here to download Figure(s): Tbat.eps

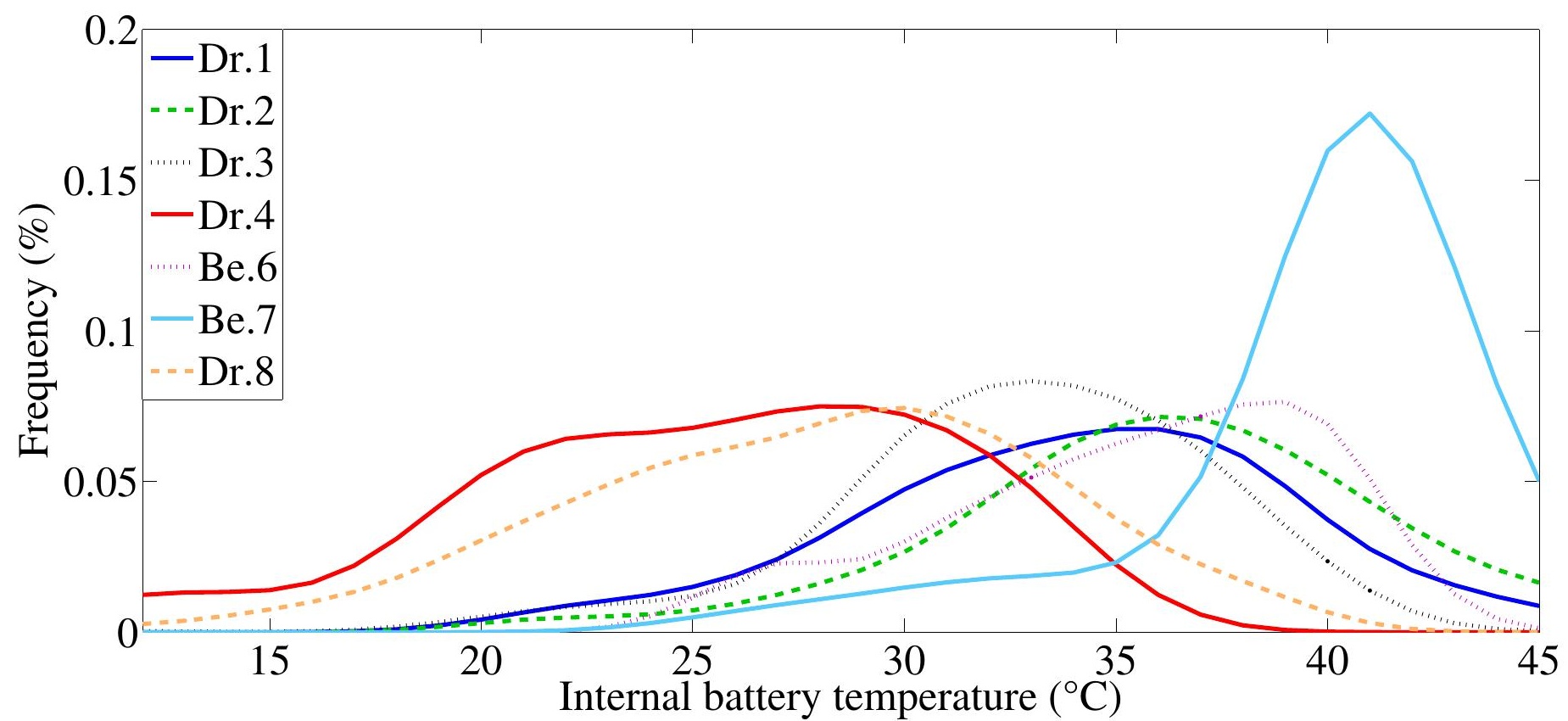




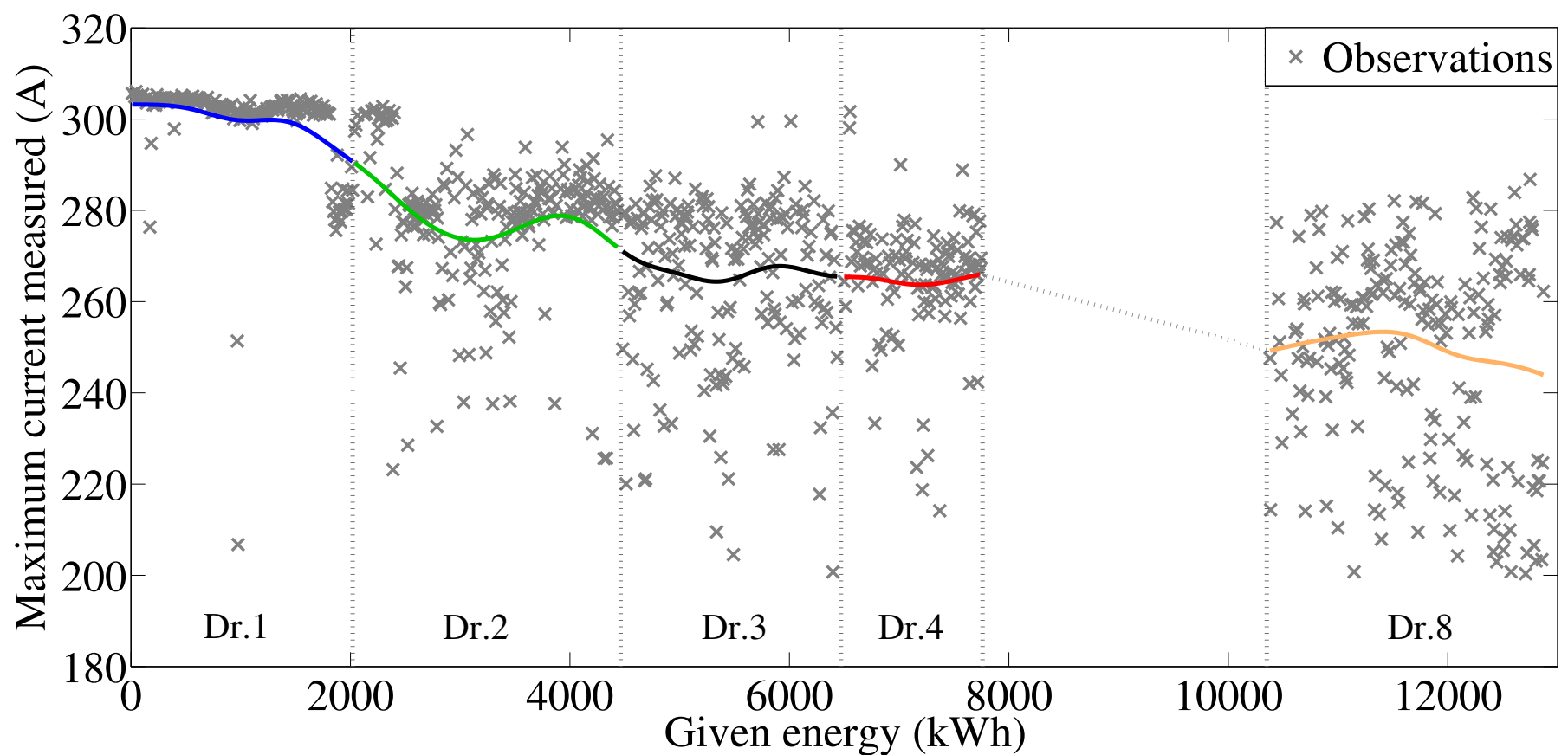


Figure 10

Click here to download Figure(s): DSOC.eps

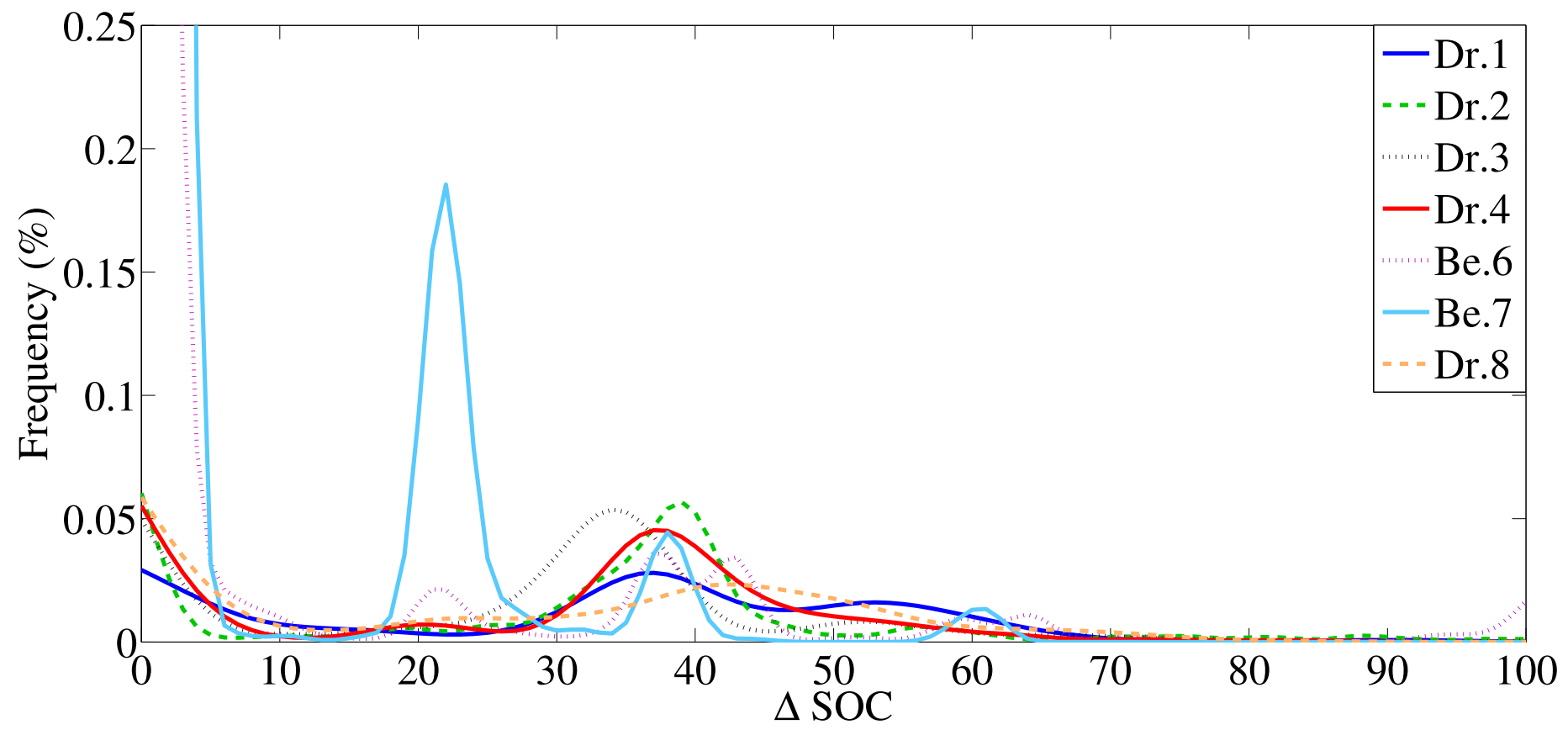




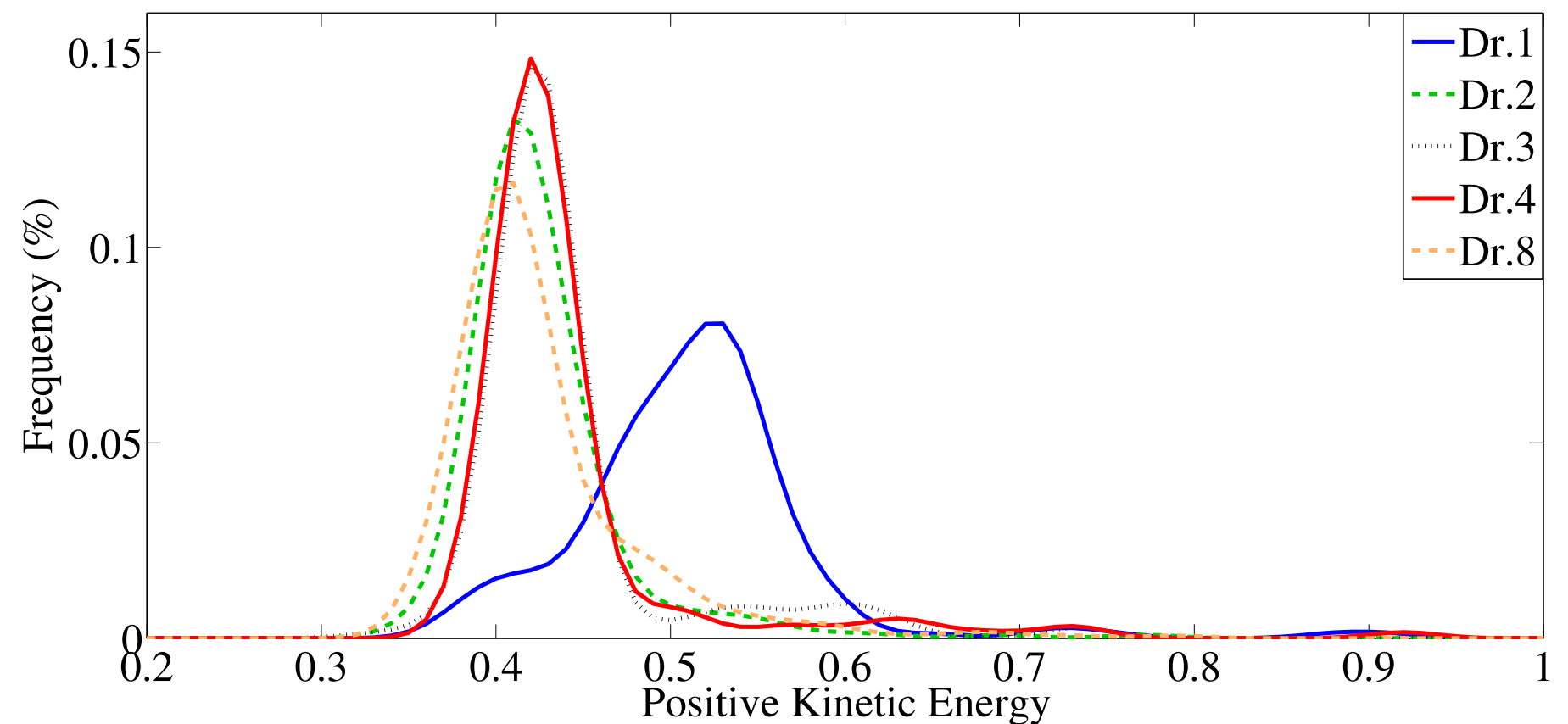


Longitude Latitude Altitude Wheels torque GPS Speed Speed I Battery I Traction

U Cell min

U Cell max

U Battery

E Bat. consumed SOC T Cell max T Battery T Cell min

$\mathrm{T}$ Ambient Time

Distance I Battery Acc. Charges number

E Bat. input E Bat. output U Accessories Kilometers
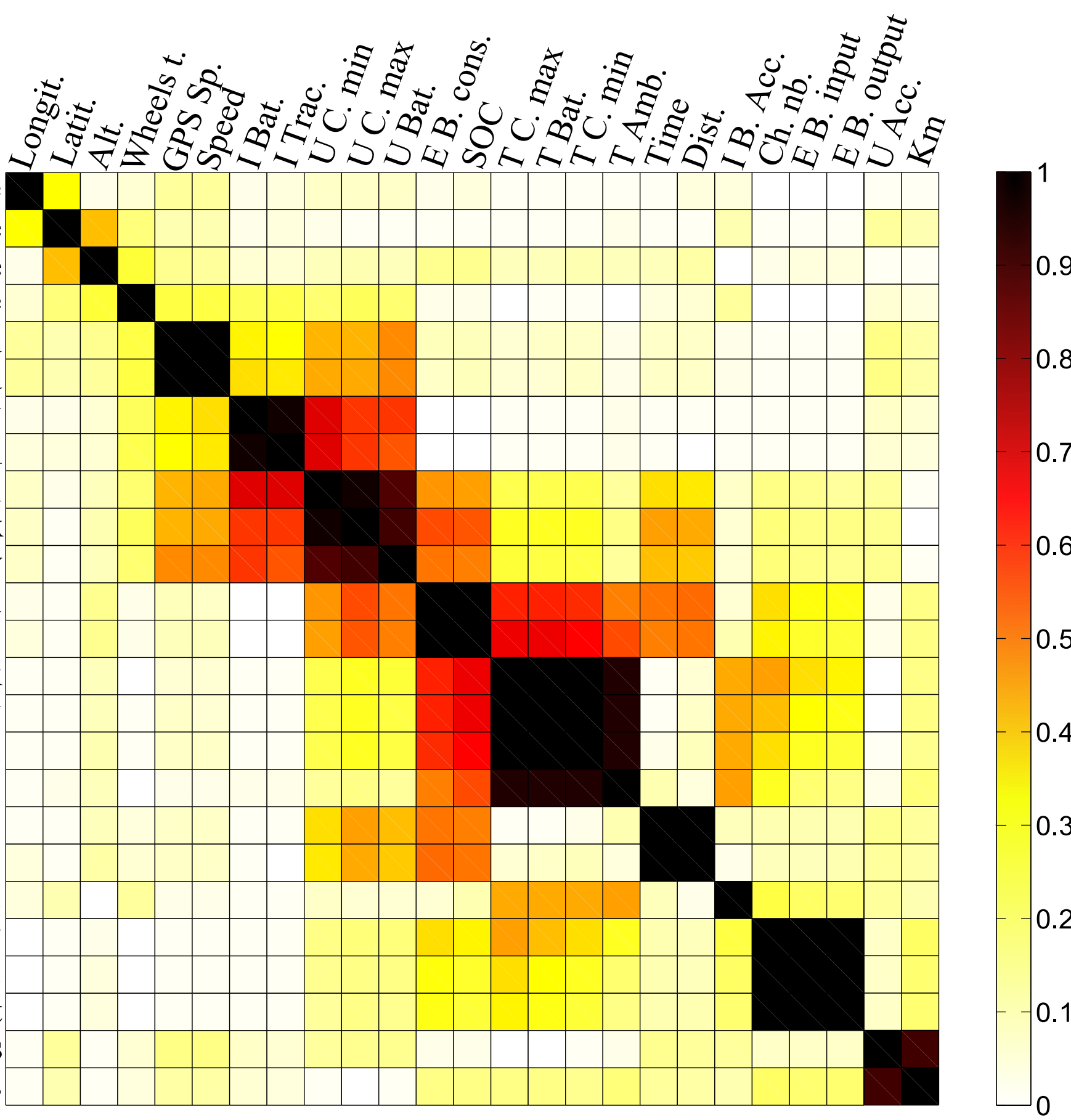
Click here to download Figure(s): Cap_hist.eps

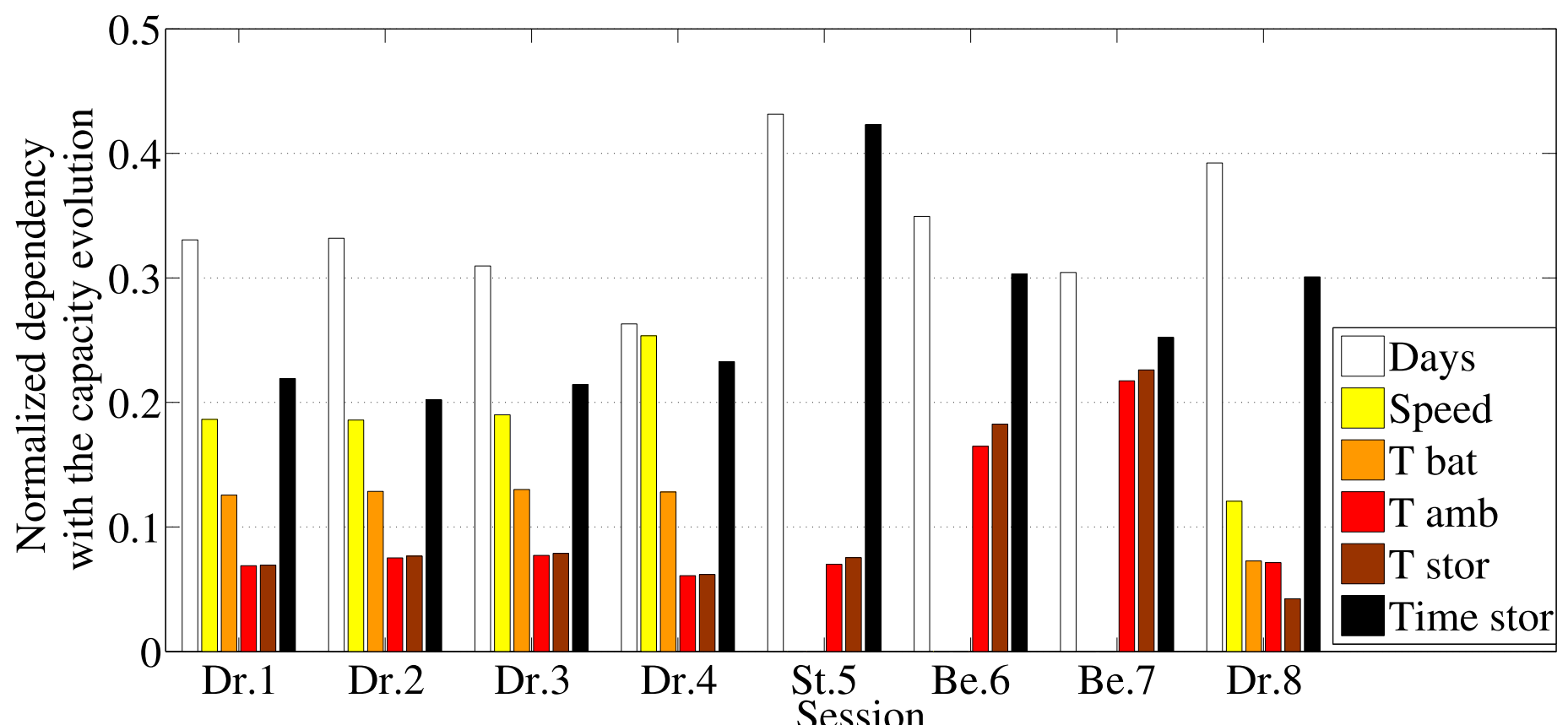

Session 
Click here to download Figure(s): Res_hist.eps

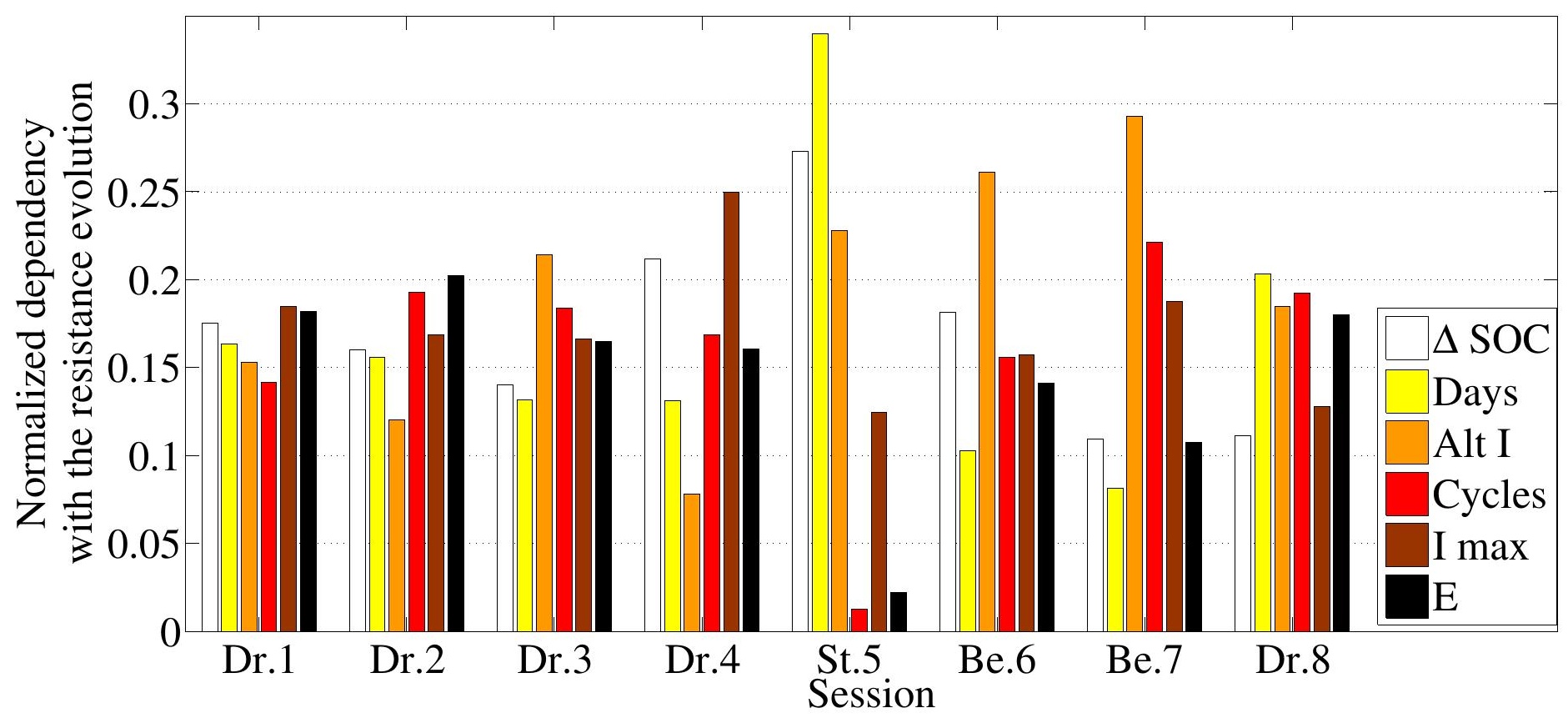


Click here to download high resolution image

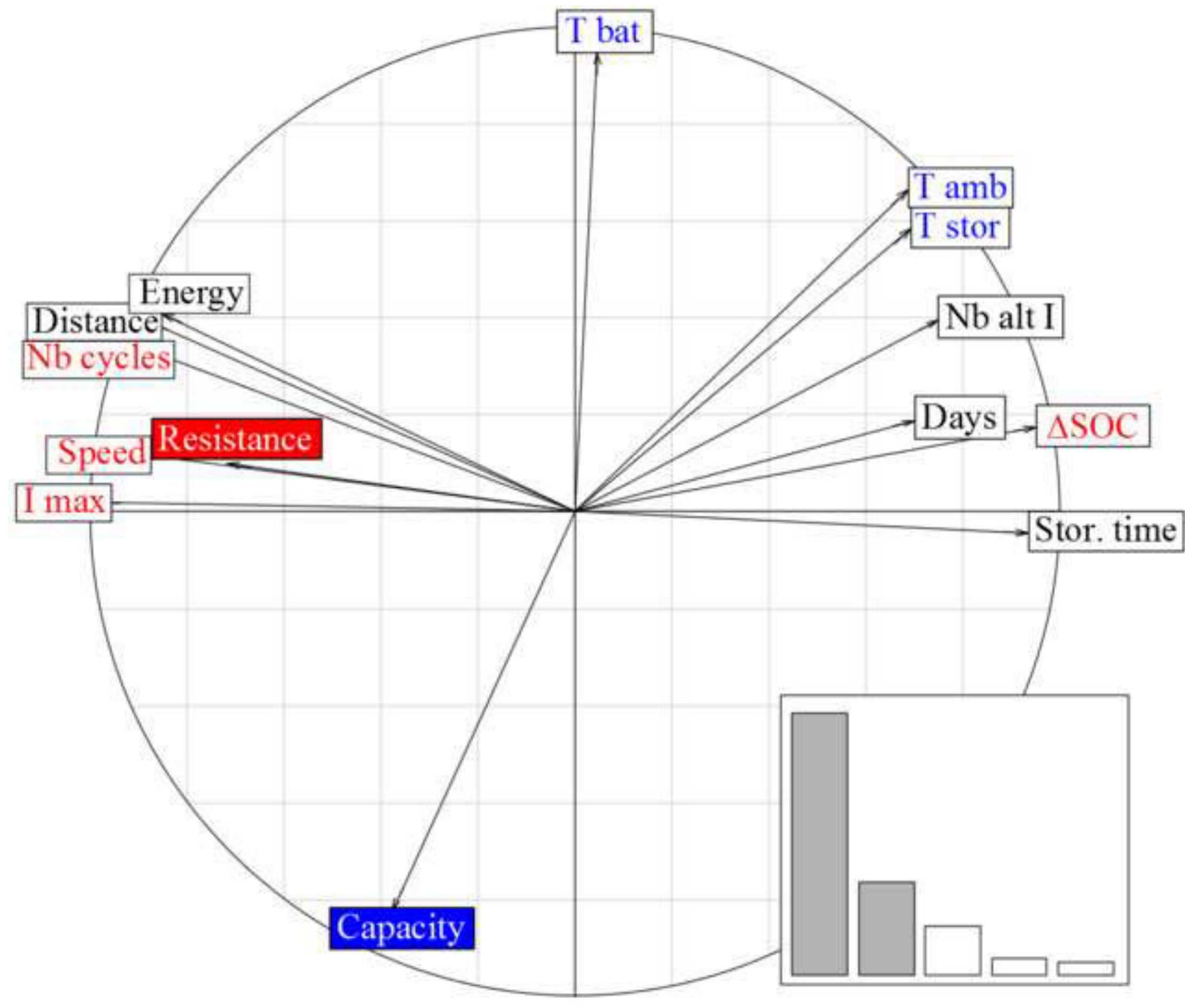


Figure 16
Click here to download Figure(s): Cap_pred.eps

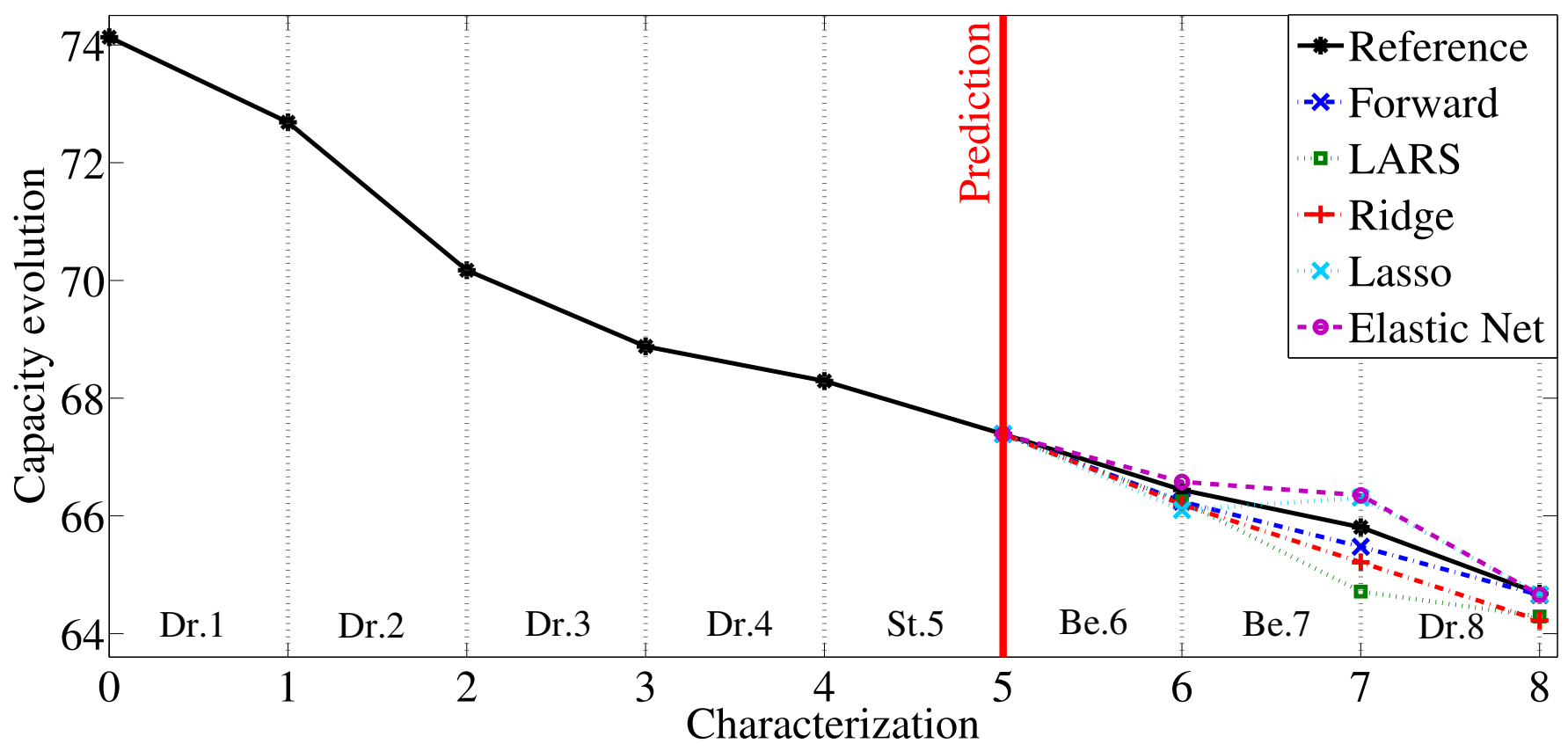




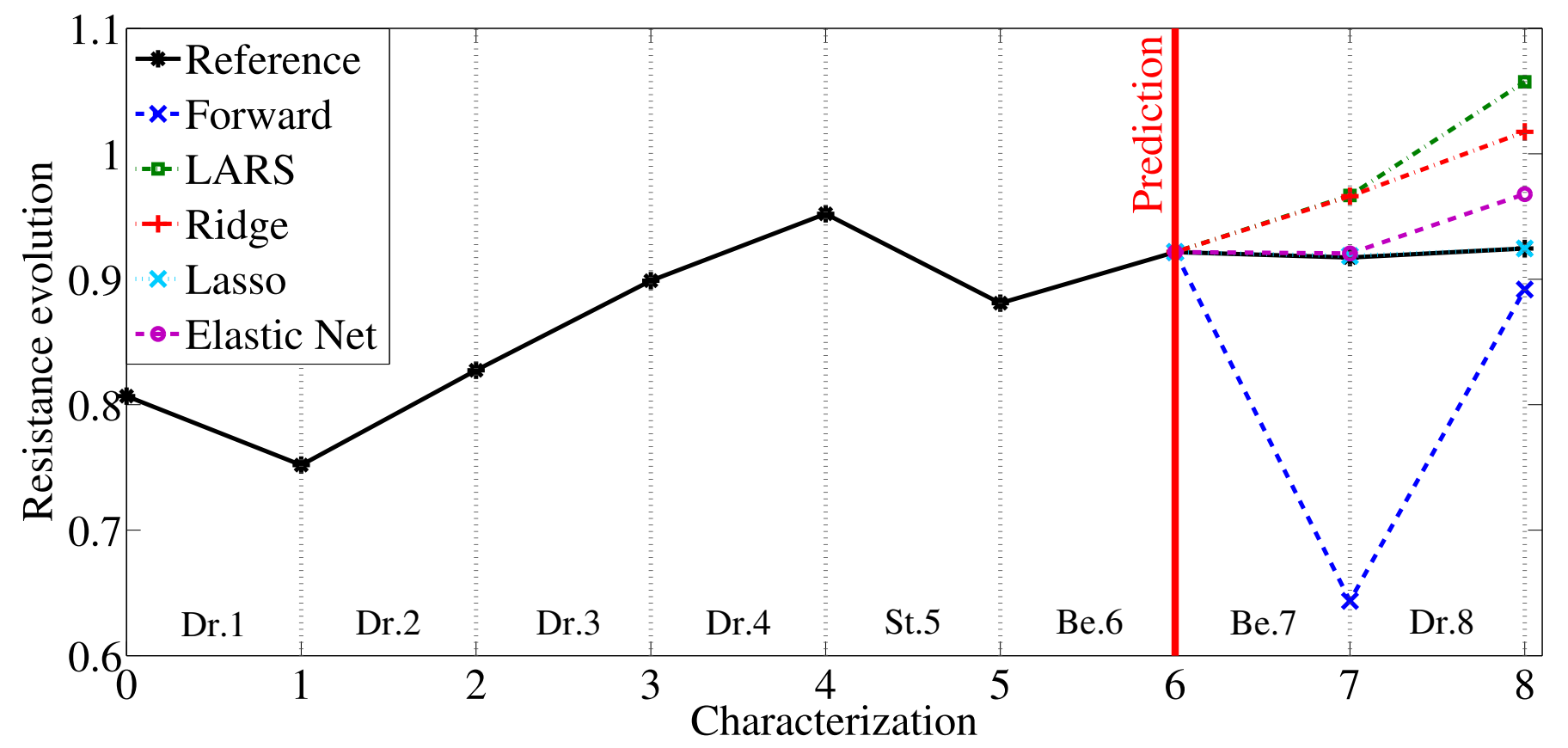

